OPEN ACCESS

Edited by:

Eleonora Grandi,

University of California, Davis,

United States

Reviewed by:

Christopher Huang,

University of Cambridge,

United Kingdom

Andrew G. Edwards,

Simula Research Laboratory, Norway

*Correspondence:

Henggui Zhang

henggui.zhang@manchester.ac.uk

Specialty section:

This article was submitted to Integrative Physiology,

a section of the journal

Frontiers in Physiology

Received: 31 July 2017 Accepted: 08 November 2017 Published: 23 November 2017

Citation:

Ni H, Whittaker DG, Wang W, Giles WR, Narayan SM and Zhang $H$

(2017) Synergistic Anti-arrhythmic Effects in Human Atria with Combined Use of Sodium Blockers and Acacetin.

Front. Physiol. 8:946

doi: 10.3389/fphys.2017.00946

\section{Synergistic Anti-arrhythmic Effects in Human Atria with Combined Use of Sodium Blockers and Acacetin}

\author{
Haibo $\mathrm{Ni}^{1,2,3}{ }^{1}$, Dominic G. Whittaker ${ }^{1}$, Wei Wang ${ }^{1}$, Wayne R. Giles ${ }^{4}$, Sanjiv M. Narayan ${ }^{5}$ and \\ Henggui Zhang $1,2,3,6 *$ \\ ${ }^{1}$ Biological Physics Group, University of Manchester, Manchester, United Kingdom, ${ }^{2}$ Space Institute of Southern China, \\ Shenzhen, China, ${ }^{3}$ Key Laboratory of Medical Electrophysiology, Ministry of Education, Collaborative Innovation Center for \\ Prevention and Treatment of Cardiovascular Disease/Institute of Cardiovascular Research, Southwest Medical University, \\ Luzhou, China, ${ }^{4}$ Faculties of Kinesiology and Medicine, University of Calgary, Calgary, AB, Canada, ${ }^{5}$ Department of \\ Medicine, Stanford University School of Medicine, Stanford, CA, United States, ${ }^{6}$ School of Computer Science and \\ Technology, Harbin Institute of Technology, Harbin, China
}

Atrial fibrillation (AF) is the most common cardiac arrhythmia. Developing effective and safe anti-AF drugs remains an unmet challenge. Simultaneous block of both atrial-specific ultra-rapid delayed rectifier potassium $\left(\mathrm{K}^{+}\right)$current $\left(\mathrm{I}_{\mathrm{Kur}}\right)$ and the $\mathrm{Na}^{+}$ current $\left(I_{\mathrm{Na}}\right)$ has been hypothesized to be anti-AF, without inducing significant QT prolongation and ventricular side effects. However, the antiarrhythmic advantage of simultaneously blocking these two channels vs. individual block in the setting of AF-induced electrical remodeling remains to be documented. Furthermore, many $I_{\text {Kur }}$ blockers such as acacetin and AVE0118, partially inhibit other $\mathrm{K}^{+}$currents in the atria. Whether this multi- $\mathrm{K}^{+}$-block produces greater anti-AF effects compared with

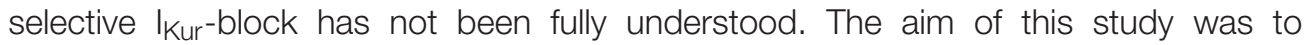
use computer models to (i) assess the impact of multi- $\mathrm{K}^{+}$-block as exhibited by many $I_{\text {Kur }}$ blokers, and (ii) evaluate the antiarrhythmic effect of blocking $I_{\text {Kur }}$ and $I_{\mathrm{Na}}$, either alone or in combination, on atrial and ventricular electrical excitation and recovery in the setting of AF-induced electrical-remodeling. Contemporary mathematical models of human atrial and ventricular cells were modified to incorporate dose-dependent actions of acacetin (a multichannel blocker primarily inhibiting $I_{\text {Kur }}$ while less potently blocking $I_{t o}, I_{K_{r}}$, and $I_{K_{s}}$ ). Rate- and atrial-selective inhibition of $I_{\mathrm{Na}}$ was also incorporated into the models. These single myocyte models were then incorporated into multicellular two-dimensional (2D) and three-dimensional (3D) anatomical models of the human atria. As expected, application of $I_{\text {Kur }}$ blocker produced pronounced action potential duration (APD) prolongation in atrial myocytes. Furthermore, combined multiple $\mathrm{K}^{+}$-channel block that mimicked the effects of acacetin exhibited synergistic APD prolongations. Synergistically anti-AF effects following inhibition of $\mathrm{I}_{\mathrm{Na}}$ and combined $\mathrm{I}_{\mathrm{Kur}} / \mathrm{K}^{+}$-channels were also observed. The attainable maximal AF-selectivity of $I_{\mathrm{Na}}$ inhibition was greatly augmented by blocking $I_{K u r}$ or multiple $\mathrm{K}^{+}$-currents in the atrial myocytes. This enhanced anti-arrhythmic effects of combined block of $\mathrm{Na}^{+}$- and $\mathrm{K}^{+}$-channels were also seen in $2 \mathrm{D}$ and $3 \mathrm{D}$ simulations; specially, there was an enhanced efficacy in terminating re-entrant excitation 
waves, exerting improved antiarrhythmic effects in the human atria as compared to a single-channel block. However, in the human ventricular myocytes and tissue, cellular repolarization and computed QT intervals were modestly affected in the presence of actions of acacetin and $I_{\mathrm{Na}}$ blockers (either alone or in combination). In conclusion, this study demonstrates synergistic antiarrhythmic benefits of combined block of $I_{\text {Kur }}$ and $I_{\mathrm{Na}}$, as well as those of $I_{\mathrm{Na}}$ and combined multi $\mathrm{K}^{+}$-current block of acacetin, without significant alterations of ventricular repolarization and QT intervals. This approach may be a valuable strategy for the treatment of AF.

Keywords: atrial-selective block, atrial fibrillation, sodium and potassium current block, multiscale simulation, synergistic antiarrhythmic effect

\section{INTRODUCTION}

Despite recent advances in the management of Atrial fibrillation (AF), the world's most common cardiac arrhythmia (Dobrev et al., 2012; Nattel and Dobrev, 2017), developing effective and safe antiarrhythmic drugs for treatment of $\mathrm{AF}$ remains challenging (Aguilar-Shardonofsky et al., 2012; Aguilar et al., 2015). Frequently these antiarrhythmic agents promote ventricular arrhythmias (Dobrev et al., 2012; Woods and Olgin, 2014; Voigt and Dobrev, 2016) by prolonging cellular action potential durations (APDs). The associated QT-interval prolongation can lead to life-threatening consequences. Developing atrial-selective drugs is acknowledged to be a current strategy for the treatment of AF (Burashnikov et al., 2007).

Atrial and ventricular tissues show intrinsic regional differences in their cellular ion channel properties, thus suggesting a basis for developing atrial-selective drugs. For example, the atrial and ventricular fast sodium $\left(\mathrm{Na}^{+}\right)$channel currents $\left(\mathrm{I}_{\mathrm{Na}}\right)$ exhibit different voltage-dependent inactivation properties, opening the opportunity for atrial-selective $\mathrm{Na}^{+}$ channel blockade (Burashnikov et al., 2007; Antzelevitch and Burashnikov, 2009; Zygmunt et al., 2011). Previous simulation studies have demonstrated that by optimizing state-dependent $\mathrm{Na}^{+}$-channel blocking dynamics (i.e., drug-channel interaction parameters), atrial-selective block of $\mathrm{I}_{\mathrm{Na}}$ could be achieved and that could maximize pharmaceutical effects on the atria while minimizing their proarrhythmic actions in the ventricles (Aguilar-Shardonofsky et al., 2012; Aguilar et al., 2015).

Another tissue-specific difference between the atria and ventricles is that the ultra-rapid delayed rectifier potassium current $\left(\mathrm{I}_{\mathrm{Kur}}\right.$, carried by the $\mathrm{K}_{\mathrm{V}} 1.5$ channel) contributes to repolarization in the atria but plays little role in the ventricles (Tamargo et al., 2009; Ravens and Wettwer, 2011). Recent studies suggest that atrial-selective blockade of $\mathrm{I}_{\text {Kur }}$ may be an effective pharmacological treatment of AF (Li et al., 2008; Pavri et al., 2012; Loose et al., 2014; Ford et al., 2016). Although the efficacy of $\mathrm{I}_{\text {Kur }}$ block in the treatment of AF remains controversial (Burashnikov and Antzelevitch, 2008), multiple $\mathrm{I}_{\text {Kur }}$ blockers have been developed (Tamargo et al., 2009; Loose et al., 2014; Wettwer and Terlau, 2014; Ford et al., 2016). Interestingly, these $\mathrm{I}_{\text {Kur }}$ blockers actually target multiple channels, and are known to inhibit other $\mathrm{K}^{+}$currents including $\mathrm{I}_{\text {to }}$ and $\mathrm{I}_{\mathrm{K}, \mathrm{ACh}}$ in the atria (Burashnikov and Antzelevitch, 2008). Examples of such blockers include AVE0118 (Gögelein et al., 2004), AVE1231 (Wirth et al., 2007), AZD7009 (Persson et al., 2005), and acacetin (Li et al., 2008). Among these channel blockers, acacetin, a natural flavone initially isolated from a traditional Chinese medicine Xuelianhua, potently blocks $\mathrm{I}_{\mathrm{Kur}}, \mathrm{I}_{\mathrm{to}}$, and $\mathrm{I}_{\mathrm{K}, \mathrm{ACh}}$, and has a smaller potency in inhibiting $\mathrm{I}_{\mathrm{Kr}}$ and $\mathrm{I}_{\mathrm{Ks}}$ (Li et al., 2008), similar to AVE0118 (Gögelein et al., 2004; Haan et al., 2006). Acacetin is regarded as a promising atrial-selective agent for the treatment of $\mathrm{AF}$ (Li et al., 2008). However, the actions of acacetin on atrial electrophysiology, especially its effects following AF-induced electrical remodeling of atrial electrophysiological properties (Dobrev et al., 2012), remain to be elucidated. Furthermore, since most $\mathrm{I}_{\mathrm{Kur}}$ blockers inhibit other $\mathrm{K}^{+}$channels, the question whether the "additional" inhibitive actions produce favorable antiarrhythmic effects has not been addressed thoroughly. A better understanding of these effects of modulating multiple ion channels on atrial excitation and recovery/repolarization may provide insights into evaluating and developing antiarrhythmic drugs.

Interestingly, simultaneous multiple-channel blocking of both depolarization and repolarization currents is attracting more attention since empirical observations suggest that such multichannel blockers generally mediate more effective antiarrhythmic effects (Kirchhoff et al., 2015; Reiffel et al., 2015; Hartmann et al., 2016). A recent numerical and experimental study on the canine heart (Aguilar et al., 2015) suggested that blocking $\mathrm{K}^{+}$ currents enhanced the anti-arrhythmic effects and AF-selectivity of $\mathrm{I}_{\mathrm{Na}}$ blockade. In their study, $\mathrm{I}_{\mathrm{Kur}}$ block was modeled using a simple pore block scheme by reducing the conductance of the channel. As the kinetics of drug action plays an important role in the effects of $\mathrm{I}_{\mathrm{Kur}}$ blockers (Scholz et al., 2013; Ellinwood et al., 2017), in simulating $I_{\text {Kur }}$ block a state-dependent block model reproducing a realistic blocker is more favorable. Once again, the effects of combined $\mathrm{I}_{\mathrm{Na}}$ and $\mathrm{I}_{\mathrm{Kur}}$ block on the human atria, especially in the setting of AF-induced electrical remodeling which reduced $\mathrm{I}_{\mathrm{Kur}}$, remain to be elucidated. It is also unclear how multiple-channel blockade may affect QT interval.

In the present study, it was hypothesized that combined block of $\mathrm{I}_{\mathrm{Na}}$ and $\mathrm{K}^{+}$-currents (predominantly $\mathrm{I}_{\mathrm{Kur}}$ ) could produce antiarrhythmic benefits compared with the application of either blocker alone in the setting of AF-induced electrical remodeling. We have tested the hypothesis with the following three aims: (i) to identify and illustrate the effects of the realistic $I_{K u r}$ 
blocker, acacetin, on atrial electrophysiology following AFrelated remodeling; (ii) to assess whether combined $\mathrm{I}_{\mathrm{Na}}$ and $\mathrm{I}_{\text {Kur }}$ block produce synergistic antiarrhythmic effects; and (iii) to investigate the action of such drug combinations on ventricular electrophysiology.

\section{METHODS}

\section{Modeling Electrophysiology of the Human Heart}

To simulate human atrial electrophysiology, an updated Colman et al. model for atrial electrophysiology (Colman et al., 2013, 2017) was used. For in silico study of effects of chronic AF(cAF) induced electrophysiological remodeling on the atria, we incorporated the CAF model parameters from our previous study (Colman et al., 2013) into the updated atrial single cell model (for details please see Online Supplement Material 1.1).

To assess the effects of the anti-AF drugs on the human ventricles, simulations were performed to investigate the actions of the anti-AF drugs on the ventricular AP, $\mathrm{I}_{\mathrm{Na}}$ and $\mathrm{QT}$ intervals in the electrograms. In these simulations, the mathematical model developed by O'Hara et al. (2011) was used to represent the ventricular electrophysiology. Additionally, the $\mathrm{I}_{\mathrm{Na}}$ formulation in the model was replaced by the one in the Luo-Rudy model (Luo and Rudy, 1994), which enabled electrical excitation to propagate in the tissue model.

More detailed descriptions of the electrophysiological models of human atrial and ventricular cells are given in Online Supplementary Material 1.1.

\section{Modeling State-Dependent $I_{\mathrm{Na}}$ Block}

As in previous studies (Aguilar-Shardonofsky et al., 2012; Aguilar et al., 2015), $\mathrm{I}_{\mathrm{Na}}$ block was simulated using a guarded receptor model with dynamical drug-channel interactions. This approach allows for investigations of the role of the specified parameters for selected $I_{N a}$ blockers, and effects of combined $I_{K u r}$ block on the atrial selectivity of $\mathrm{Na}^{+}$-channel block. The guarded receptor model considers the binding and unbinding kinetics of the drug to $\mathrm{I}_{\mathrm{Na}}$ channels in a drug concentration-dependent manner. They can be described by first-order transition equations (Aguilar-Shardonofsky et al., 2012; Aguilar et al., 2015). It was also assumed that the drug predominantly binds to the activated and/or inactivated states of $\mathrm{I}_{\mathrm{Na}}$. The blockade of $\mathrm{I}_{\mathrm{Na}}$ is given by Aguilar-Shardonofsky et al. (2012) and Aguilar et al. (2015):

$$
\begin{array}{r}
I_{\mathrm{Na}}=g_{\mathrm{Na}}\left(1-B_{A}-B_{I}\right) m^{3} h j\left(V_{m}-E_{N a}\right) \\
\frac{d B_{A}}{d t}=K_{A}\left[D_{N a^{+}}\right] m^{3} h j\left(1-B_{A}-B_{I}\right)-L_{A} B_{A} \\
\frac{d B_{I}}{d t}=K_{I}\left[D_{\mathrm{Na}^{+}}\right](1-h)\left(1-B_{A}-B_{I}\right)-L_{I} B_{I}
\end{array}
$$

where $g_{\mathrm{Na}}$ is the maximum conductance of $\mathrm{I}_{\mathrm{Na}} ; B_{A}$ and $B_{I}$ are the fractional blockade of activation and inactivation channels; $m$ is the activation gate state variable, $h$ and $j$ are the inactivation gate state variables; $V_{\mathrm{m}}$ the transmembrane potential; $E_{N a}$ the reversal potential of $\mathrm{Na}^{+} ; K_{A}, K_{I}$ the binding constants and $L_{A}$, $L_{I}$ the unbinding constants; $\left[D_{\mathrm{Na}^{+}}\right]$is the concentration of a
$\mathrm{Na}^{+}$-blocker. As in previous studies (Aguilar-Shardonofsky et al., 2012; Aguilar et al., 2015), a concentration of $60 \mu \mathrm{M}$ was utilized unless otherwise stated; this concentration was chosen based on previous experimental and modeling studies (Zhu et al., 2006; Moreno et al., 2011; Aguilar-Shardonofsky et al., 2012; Aguilar et al., 2015); a parameter set $\left(K_{A}=100 \mathrm{~ms}^{-1} \cdot \mathrm{M}^{-1}, K_{I}=100\right.$ $\mathrm{ms}^{-1} \cdot \mathrm{M}^{-1}, L_{A}=1 \mathrm{~ms}^{-1}, L_{I}=0.01 \mathrm{~ms}^{-1}$ ) was first used to represent the kinetics of an $\mathrm{I}_{\mathrm{Na}}$-selective blocker.

In our investigations of the AF-selectivity of $\mathrm{I}_{\mathrm{Na}}$ block following AF-remodeling, the binding and unbinding constants of the $\mathrm{I}_{\mathrm{Na}}$ blockers were varied to evaluate the dependence of $\mathrm{I}_{\mathrm{Na}}$ block on these parameters, and whether an atrial-selective antiAF action could be achieved in cAF-remodeled myoctes. The AFselectivity of $\mathrm{Na}^{+}$-channel blockade was defined as the product of atrial-selectivity, rate-selectivity and block efficacy. With fractional block $\left(B_{\mathrm{f}}\right)$ by $\mathrm{Na}^{+}$-channel blockers being measured as the relative reduction in the peak of $\mathrm{I}_{\mathrm{Na}}$, the rate-selectivity was defined as the ratio of $B_{\mathrm{f}}$ measured in an atrial myocyte paced at $6 \mathrm{~Hz}$ to that paced at $1 \mathrm{~Hz}$ (Aguilar-Shardonofsky et al., 2012; Aguilar et al., 2015). Atrial-selectivity was used to determine the extent of atrial-ventricular difference in response to each drug. This was represented by the ratio of $B_{\mathrm{f}}$ observed from an atrial myocyte to that of a ventricular cell both paced at $1 \mathrm{~Hz}$. In this study, we defined block efficacy $(E)$ as:

$$
E=\frac{1.0}{1.0+\left(\frac{0.5}{B_{\mathrm{f}, 6 \mathrm{~Hz}}}\right)^{4}}
$$

where $B_{f, 6 \mathrm{~Hz}}$ is the fractional block of $\mathrm{I}_{\mathrm{Na}}$ measured in an atrial cell paced at $6 \mathrm{~Hz}$. Different from Aguilar et al. (2015), we introduced block efficacy to constrain the measure of AFselectivity when the fractional block observed in a ventricular cell paced was minimal (and could result in a great atrialselectivity), which otherwise could give a great value in AFselectivity regardless of a small $B_{\mathrm{f}, 6 \mathrm{~Hz}}$.

To assess the dependence of the AF-selectivity of $I_{\mathrm{Na}}$ block on the drug action kinetics, the unbinding constants $L_{A}$ and $L_{I}$ were first varied over a parameter space from $10^{-5}$ to $10^{0} \mathrm{~ms}^{-1}$, while $K_{A}$ and $K_{I}$ were fixed (see Figure S6 of online Supplementary Materials for more details). The resultant unbinding constants were used in subsequent optimizations varying $K_{A}$ and $K_{I}$. The parameter space was $\{1,10,100,500,2,500,10,000\}$ for $K_{A}$ and $\{1,10,100,200,500,2,500\}$ for $K_{I}$. The parameter space fell into a likely range of $\mathrm{I}_{\mathrm{Na}}$ blockers as summarized in AguilarShardonofsky et al. (2012).

\section{Modeling Effects of Acacetin on Atrial and Ventricular Electrophysiology}

Acacetin was the chosen $\mathrm{I}_{\mathrm{Kur}}$ blocker in the present study. To reveal the functional effects of (i) pure $\mathrm{I}_{\text {Kur }}$ block vs. (ii) the effects of combined $\mathrm{K}^{+}$currents block by acacetin on human atrial electrophysiology, the actions of acacetin were modeled by considering its effects on (a) $I_{K u r}$ only, and (b) all the respective $\mathrm{K}^{+}$currents as detailed in Table 1. This approach allows for modeling the effects of the selective $\mathrm{I}_{\mathrm{Kur}}$ block as well as uncovering the role of "additional" inhibitory effects of acacetin on other $\mathrm{K}^{+}$currents. 
TABLE 1 | Concentration-dependent block of $\mathrm{K}^{+}$-currents by acacetin ( $\mathrm{Li}$ et al., 2008; Wu et al., 2011).

\begin{tabular}{lcccc}
\hline & $\mathbf{I}_{\mathbf{K u r}}$ & $\mathbf{I}_{\text {to }}$ & $\mathbf{I}_{\mathbf{K r}}$ & $\mathbf{I}_{\mathbf{K s}}$ \\
\hline $\mathrm{IC}_{50}(\mu \mathrm{M})$ & $3-3.2$ & 9.3 & 32.4 & 81.4 \\
Hill coefficient & 0.8 & 0.9 & 0.9 & 0.8 \\
Fractional inhibition at $3.2 \mu \mathrm{M}$ & $50 \%$ & $28 \%$ & $11 \%$ & $7 \%$ \\
\hline
\end{tabular}

\section{Modeling Effect of Acacetin on IKur}

Previous modeling studies have demonstrated the important role of the kinetic properties of drug actions in $\mathrm{I}_{\text {Kur }}$ block (Tsujimae et al., 2008; Almquist et al., 2010; Scholz et al., 2013). In addition, the pharmaceutical effects of acacetin on $\mathrm{I}_{\mathrm{Kur}}$ are characterized by use- and rate-dependencies (Wu et al., 2011), which have also been observed in other $\mathrm{I}_{\text {Kur }}$ blockers (Pavri et al., 2012; Ford et al., 2016). Therefore, it was necessary to adopt a statedependent block model (Brennan et al., 2009) for simulating the blockade of $I_{\text {Kur }}$ by acacetin. Similar to our approach for modeling $\mathrm{I}_{\mathrm{Na}}$ block, the binding and unbinding kinetics of a drug was described by a first-order transition equation, in contrast to simulating $\mathrm{I}_{\mathrm{Kur}}$ block by reducing its conductance in Aguilar et al. (2015). Experimental studies revealed that acacetin binds to both the open and closed gates of $\mathrm{K}_{\mathrm{V}} 1.5$ (Wu et al., 2011). Therefore, following the guarded receptor formulas given in Equations (1-3), the formulation of inactivation-state binding and unbinding kinetics in $\mathrm{I}_{\mathrm{Na}}$ block was modified to simulate the closed-state block of $I_{\text {Kur }}$ by acacetin. The guarded receptor model of $\mathrm{I}_{\text {Kur }}$ block by acacetin is given by:

$$
\begin{aligned}
I_{\mathrm{Kur}}= & g_{\mathrm{Kur}}\left(1-B_{O}-B_{C}\right) a i\left(V_{m}-E_{K}\right) \\
\frac{d B_{O}}{d t}= & K_{O} \exp \left(Z_{K O} \frac{V_{m} F}{R T}\right)\left[D_{K^{+}}\right] a i\left(1-B_{O}-B_{c}\right) \\
& -L_{O} \exp \left(-Z_{L O} \frac{V_{m} F}{R T}\right) B_{O} \\
\frac{d B_{c}}{d t}= & K_{c} \exp \left(Z_{K c} \frac{V_{m} F}{R T}\right)\left[D_{K^{+}}\right](1-a) i\left(1-B_{O}-B_{c}\right) \\
& -L_{c} \exp \left(-Z_{L c} \frac{V_{m} F}{R T}\right) B_{c}
\end{aligned}
$$

where $g_{\mathrm{Kur}}$ is the conductance of $\mathrm{I}_{\mathrm{Kur}} ; B_{\mathrm{O}}$ and $B_{\mathrm{C}}$ are the fractional block on open and closed state variables, respectively; $a$ and $i$ are the activation and inactivation gate variables; $E_{K}$ is the reversal potential of potassium; $F, R$, and $T$ are the Faraday's constant, universal gas constant and temperature respectively. $K_{O}$ and $K_{c}$ are the binding constants; $L_{O}$ and $L_{c}$ are the unbinding constants; $Z_{K O}, Z_{L O}, Z_{K c}$ and $Z_{L c}$ are the drug charge parameters for the corresponding binding or unbinding processes; $\left[D_{K^{+}}\right]$ is the concentration of acacetin applied. The binding and unbinding parameters were obtained by fitting the model to the experimental data on the rate-dependent blockade of $\mathrm{I}_{\mathrm{Kur}}$ by acacetin (Wu et al., 2011), as detailed in Online Supplementary Material 1.1.

Figure 1 shows a simulated frequency-dependent block of IKur by acacetin, and this is compared to the experimental data (Figures 1A,B). As shown, repeating the voltage command (Figure 1B, insert) at $0.5 \mathrm{~Hz}$ resulted in an approximately $50 \%$ blockade in this current after application of $3 \mu \mathrm{M}$ acacetin. Increasing the voltage command rate to $4 \mathrm{~Hz}$ significantly increased the relative fractional block to approximately $63 \%$ (Figure 1C).

\section{Modeling Effect of Acacetin on $I_{\mathrm{to}}, \mathrm{I}_{\mathrm{Kr}}$, and $\mathrm{I}_{\mathrm{Ks}}$} In addition to inhibiting $I_{K u r}$ in the atria, acacetin potently blocks both $\mathrm{I}_{\mathrm{to}}$ and $\mathrm{I}_{\mathrm{K}, \mathrm{ACh}}$, and also modulates $\mathrm{I}_{\mathrm{Kr}}$ and $\mathrm{I}_{\mathrm{Ks}}$, exhibiting multiple $\mathrm{K}^{+}$-current block. The parameters of Hill equations describing use-dependent inhibitions of these channels by acacetin are shown in Table 1 . In the simulations, the effects of acacetin on these channels were modeled using a simple pore block model (Yuan et al., 2015). In the present study, we did not simulate the effects of acacetin on $\mathrm{I}_{\mathrm{K}, \mathrm{ACh}}$ inhibitions as the role of autonomic regulation on $\mathrm{AF}$ is beyond the scope of the study.

\section{Simulations of the Effects of Acacetin on Human Ventricle}

The effects of acacetin on human ventricular APs are unknown, although experimental data demonstrated that acacetin at $30 \mu \mathrm{M}$ did not affect the heart rate and QT interval in isolated rabbit hearts (Li et al., 2008). In the present study, it was assumed that similar effects on the $\mathrm{K}^{+}$currents $\left(\mathrm{I}_{\mathrm{to}}, \mathrm{I}_{\mathrm{Kr}}, \mathrm{I}_{\mathrm{Ks}}\right)$ in atrial myocytes could be extrapolated to the ventricular myocytes. We acknowledge that $\mathrm{I}_{\mathrm{Kur}}$ is negligible in ventricles (Ravens and Wettwer, 2011), therefore in simulations of blocking $I_{K u r}$ alone, the ventricular electrophysiology was not affected.

\section{Tissue Models}

The effects of acacetin and $\mathrm{I}_{\mathrm{Na}}$ blockers on atrial and ventricular electrophysiology were further evaluated using tissue models. The monodomain equation (Clayton et al., 2011) was employed to simulate the excitation wave propagation in the myocardium. 1D models of human atrial strands were used to quantify the effects of channel blockers on atrial conduction velocity and APD restitution properties. Changes in ventricular depolarization and repolarization in response to these drugs were evaluated using a 1D model representing a transmural strand of ventricular tissue. In order to evaluate the antiarrhythmic effects of the channel blockers on re-entrant excitations in atria in the setting of cAF-induced remodeling, both idealized 2D models representing an isotropic slab of atrial tissue and an anatomically accurate 3D model of the human atria (Aslanidi et al., 2011; Colman et al., 2013, 2017; Whittaker et al., 2017) were employed to simulate the behavior of re-entrant excitations in atrial tissue. Pseudo-ECGs (pECGs) (Gima and Rudy, 2002; Baher et al., 2006) were computed as a measure of the excitation rates of intissue with sprial excitation waves. Detailed descriptions of these tissue models and pECGs are given in Online Supplementary Material 1.2, 1.3.

\section{RESULTS}

The updated Colman et al. human atrial model was first used to simulate effects cAF-induced remodeling on the 


\section{A} Experiment, Wu et al. 2011
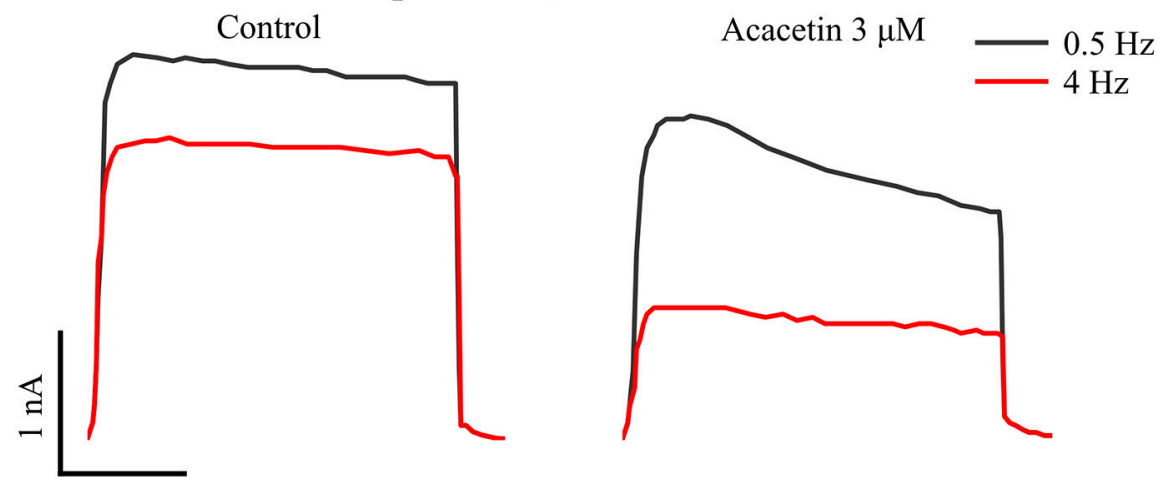

$50 \mathrm{~ms}$

B



C

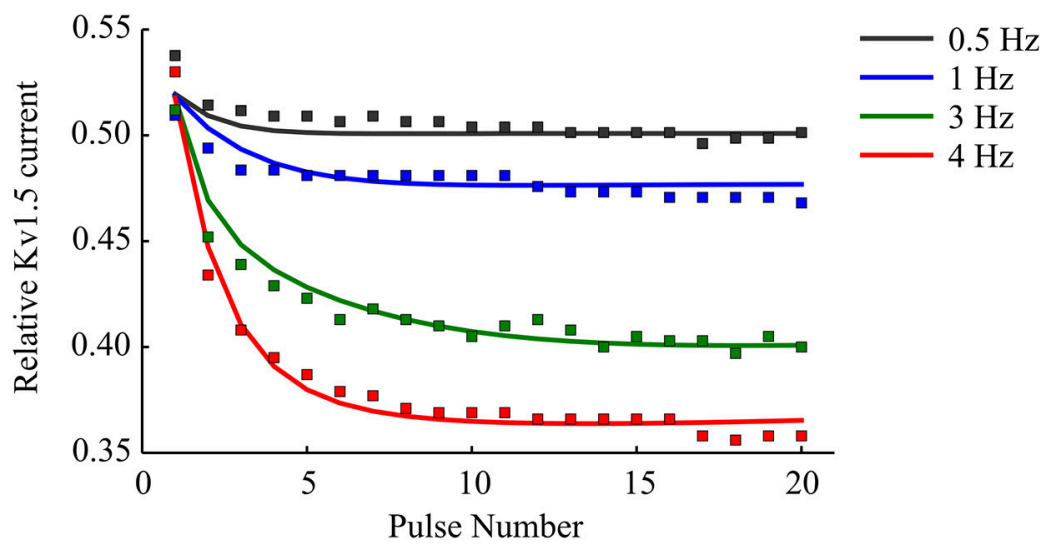

FIGURE 1 | Frequency-dependent inhibition of $I_{K u r}$ by acacetin. (A) Experimental and (B) simulated traces of $K_{V} 1.5$ channel current elicited from the 20th voltage step repeating at 0.5 and $4 \mathrm{~Hz}$ in control (left) and after exposure to $3 \mu \mathrm{M}$ of acacetin (right). (C) Relative remaining IKur following application of acacetin at various frequencies plotted against the pulse number of the voltage step. The simulated data (lines) were compared with experimental values (squares). The relative fraction was obtained by normalizing the end-step current measured from each pulse following application of acacetin to that of control. Experimental data were digitalized from Wu et al. (2011).

action potential (AP) and calcium transient (CaT). Details are presented in Online Supplementary Material 2.1. The resultant changes in APD, APD restitution and CaT following cAF-induced remodeling as compared to those under the normal condition showed good agreement with previous experimental (Bosch et al., 1999; Osaka et al., 2000; Workman et al., 2001; Dobrev and Ravens, 2003; Voigt et al., 2012) and simulation studies (Zhang et al., 2005; Grandi et al., 2011; Colman et al., 2013, 2017; Wilhelms et al., 2013). 


\section{Effects of Application of Acacetin on Human Atrial Cells}

To reveal the roles of inhibition of individual channels by acacetin in modulating cellular AP by acacetin, both the individual and combined block of $\mathrm{I}_{\mathrm{to}}, \mathrm{I}_{\mathrm{Kr}}, \mathrm{I}_{\mathrm{Kur}}$, and $\mathrm{I}_{\mathrm{Ks}}$ by acacetin $(3.2 \mu \mathrm{M})$ in simulated $\mathrm{SR}$ at cycle length $1,000 \mathrm{~ms}$ without (normal) or with cAF-related electrical remodeling were simulated. Figures 2A,B illustrates the effects of individual and combined $\mathrm{K}^{+}$channel block by acacetin on AP waveform. The alterations to APD relative to the control are summarized in Figures 2C,D.
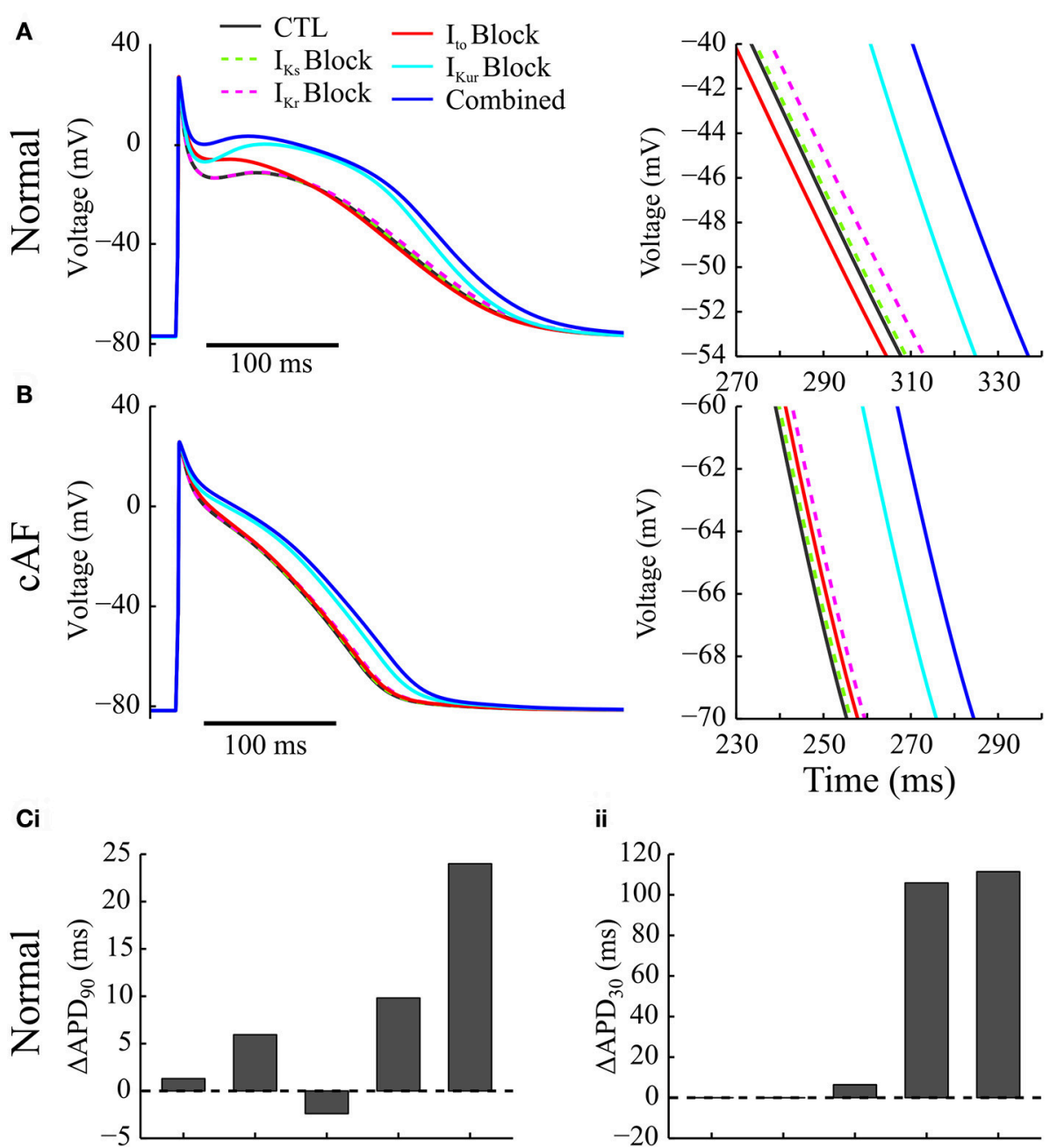

ii
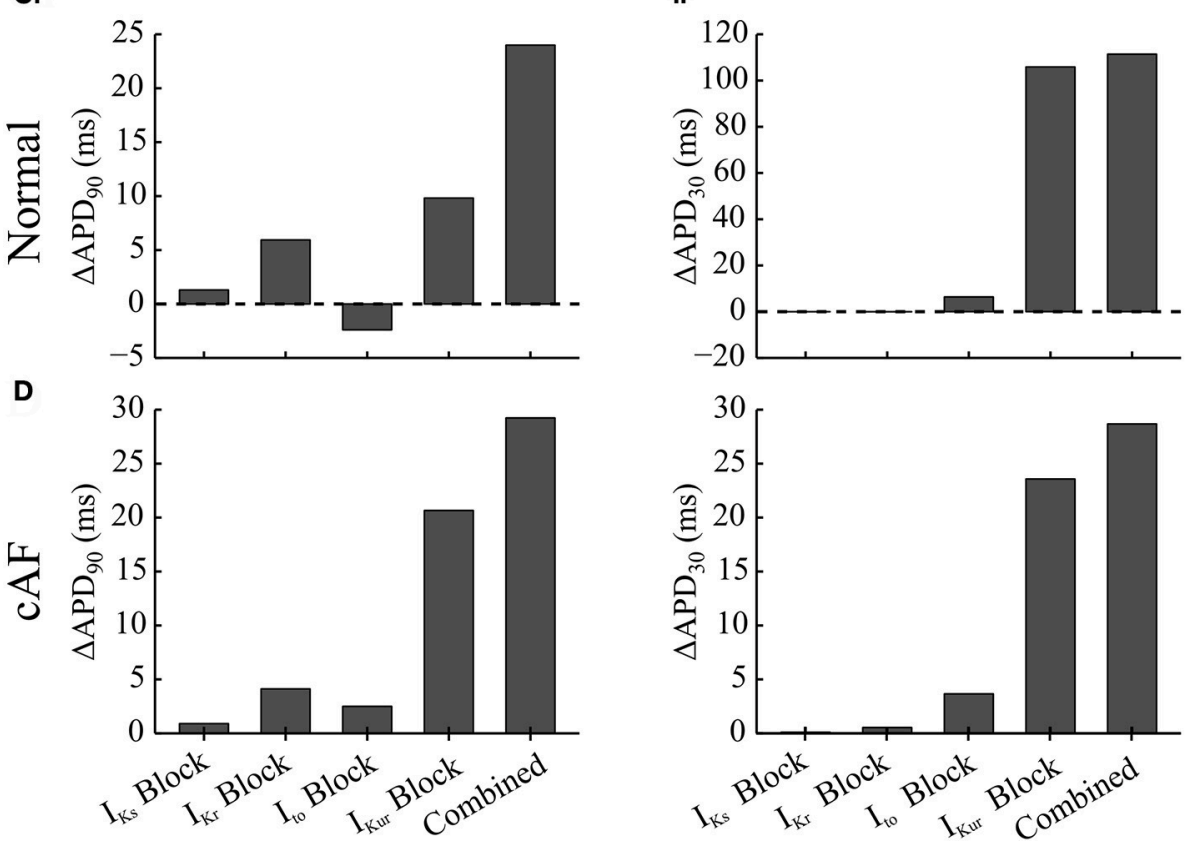

FIGURE 2 | Effects of individual vs. combined block of $\mathrm{K}^{+}$-currents by acacetin $(3.2 \mu \mathrm{M})$ on the human atrial AP in normal and cAF-remodeled myocytes paced at $1 \mathrm{~Hz}$. (A,B) Effects on the atrial AP in (A) normal and (B) cAF-remodeled myocytes; a zoomed-in view for the traces of AP during phase-3 is plotted to the right. (C,D) Alterations in the (i) APD90 and (ii) APD 30 by the simulated block obtained from atrial cells in (C) normal and (D) cAF-remodeled myocytes. 
In the absence of electrical remodeling, in normal myocytes at a cycle length of $1,000 \mathrm{~ms}$, simulated $\mathrm{I}_{\mathrm{Ks}}$ or $\mathrm{I}_{\mathrm{Kr}}$ block by acacetin $(3.2 \mu \mathrm{M})$ presented no significant alterations to the atrial AP: although the atrial repolarization was delayed by 1.3 and $5.9 \mathrm{~ms}$, respectively, the plateau phase was not affected, which is consistent with the minimal potency of acacetin on these channels (Table 1). Similar effects were also obtained from our simulated $\mathrm{I}_{\mathrm{Kr}}$ and $\mathrm{I}_{\mathrm{Ks}}$ block by the compound in the cAFremodeled atrial cells.

Selective block of $\mathrm{I}_{\text {to }}$ (alone) by acacetin elevated the atrial plateau potential in both normal and cAF-remodeled myocytes paced at $1 \mathrm{~Hz}$, and this led to modest prolongations in $\mathrm{APD}_{30}$ (by 6.4 and $3.6 \mathrm{~ms}$ for normal and AF-remodeling myocytes, respectively). The changes in $\mathrm{APD}_{90}$ due to $\mathrm{I}_{\text {to }}$ block varied between the two conditions: under normal conditions the atrial $\mathrm{APD}_{90}$ was shortened by $2.4 \mathrm{~ms}$, whereas it was prolonged by $3.7 \mathrm{~ms}$ following cAF-remodeling at a stimulus rate of $1 \mathrm{~Hz}$.

In contrast, blocking $\mathrm{I}_{\mathrm{Kur}}$ alone by acacetin resulted in a pronounced alteration to the shape and duration of the AP in both normal and cAF-remodeled myocytes. The inhibition in $\mathrm{I}_{\mathrm{Kur}}$ significantly elevated the plateau potential of atrial AP (by 7.1 and $5.7 \mathrm{mV}$ in normal and cAF-remodeled myocytes, respectively), and this was accompanied by marked prolongations in $\mathrm{APD}_{30}$ (by 105.9 and $23.6 \mathrm{~ms}$ in normal and cAF-remodeled myocytes, respectively). The prolongation in $\mathrm{APD}_{90}$ induced by the $\mathrm{I}_{\text {Kur }}$ block was $9.8 \mathrm{~ms}$ for normal atrial cells, and was more pronounced $(23.6 \mathrm{~ms})$ in cAFremodeled myocytes, despite that $\mathrm{I}_{\mathrm{Kur}}$ was down-regulated by cAF-remodeling.

We note that combined effects of acacetin $(3.2 \mu \mathrm{M})$ on multiple $\mathrm{K}^{+}$-currents produced greater alterations to the AP than those of any individual blocking effect. We have quantified effects produced by the combined block and compared it with the sum of the changes seen in each individual block. Synergistic effects were observed in the changes in $\mathrm{APD}_{90}$, represented by a further prolongation of 9.3 and $1.1 \mathrm{~ms}$ in $\mathrm{APD}_{90}$ in normal and $\mathrm{CAF}-$ remodeled myocytes, respectively. Additionally, the effects of $\mathrm{I}_{\mathrm{Kur}}$ block dominated the AP-modulation by the compound, which is consistent with the high potency of acacetin on the channel (Table 1).

\section{Effects of Sodium Blocker and Acacetin on cAF-Remodeled Atrial Myocytes and Ventricular Cells \\ Effects on Single Myocyte AP and $I_{\mathrm{Na}}$}

Individual and combined effects of $\mathrm{Na}^{+}$-block (indicated by $\left.\mathrm{Bl} \cdot \mathrm{I}_{\mathrm{Na}}\right)$ and $\mathrm{K}^{+}$-block by acacetin $(3.2 \mu \mathrm{M})$ on human atrial electrophysiology after CAF-remodeling were simulated to assess any anti-AF benefits. Effects of acacetin (representing $\mathrm{K}^{+}$-block) were simulated in different settings: (i) $\mathrm{I}_{\mathrm{Kur}}$ block alone (denoted by $\mathrm{Bl} \cdot \mathrm{I}_{\mathrm{Kur}}$ ) and (ii) combined block of all $\mathrm{K}^{+}$-currents in Table 1 (denoted by Comb $\cdot \mathrm{Bl} \cdot \mathrm{I}_{\mathrm{X}}$ ). In addition, the effects of $\mathrm{Na}^{+}$- and $\mathrm{K}^{+}$- block on human ventricular myocytes were also studied to assess the atrial-selectivity of the block. The results are shown in Figures 3A-C and quantitative measurements are shown in Figures 4A-C.
For atrial myocytes paced at $1 \mathrm{~Hz}, \mathrm{Bl} \cdot \mathrm{I}_{\mathrm{Kur}}$, and $\mathrm{Comb} \cdot \mathrm{Bl} \cdot \mathrm{I}_{\mathrm{X}}$ prolonged atrial APD (Figure 4Ai and as presented in Effects of Application of Acacetin on Human Atrial Cells) whilst their effects on peak $\mathrm{I}_{\mathrm{Na}}$ were minimal (reducing peak $\mathrm{I}_{\mathrm{Na}}$ by less than $0.3 \%)$. Bl $\cdot \mathrm{I}_{\mathrm{Na}}$ alone slightly reduced the peak $\mathrm{I}_{\mathrm{Na}}$ by $1.63 \%$ without affecting the APD. The fractional inhibition in $\mathrm{I}_{\mathrm{Na}}$ by $\mathrm{I}_{\mathrm{Na}}$-block was slightly increased by the addition of $\mathrm{Bl} \cdot \mathrm{I}_{\mathrm{Kur}}$ or Comb·Bl.IX (Figure 4Aii). In the ventricles, the simulated application of acacetin induced a prolongation of $19.5 \mathrm{~ms}$ in $\mathrm{APD}_{90}$ compared with that in control (drug-free) condition (Figures 3B, 4Ci). Bl- $\mathrm{I}_{\mathrm{Na}}$ alone showed a negligible inhibitory effect on the ventricular $\mathrm{I}_{\mathrm{Na}}$ (by $0.42 \%$ ), which was also not affected by combining $\mathrm{Bl} \cdot \mathrm{I}_{\mathrm{Na}}$ and Comb $\cdot \mathrm{Bl} \cdot \mathrm{I}_{\mathrm{X}}$ (Figure $4 \mathrm{Cii}$ ).

In atrial myocytes paced at $6 \mathrm{~Hz}, \mathrm{AP}$ alternans were observed under the drug-free condition (Figure 3Ci): the APD varied between 100.1 and $88.1 \mathrm{~ms}$. In the presence of AP alternans, the changes in APD by the $\mathrm{Na}^{+}$- and $\mathrm{K}^{+}$- blockers were quantified by comparing the corresponding big APs at baseline and after drug actions. These values were selected based on the characteristics of AP (APD prolongations seen in the long AP, and reduced $\mathrm{I}_{\mathrm{Na}}$ for the short AP) that may be anti-arrhythmic. The fractional reductions in peak $\mathrm{I}_{\mathrm{Na}}$ were calculated from the $\mathrm{I}_{\mathrm{Na}}$ associated with the shorter APs. The results showed that applying Bl. $\mathrm{I}_{\mathrm{Kur}}$ or Comb.Bl-IX alone both abolished the AP alternans while prolonging the APD to 116.3 and $126.3 \mathrm{~ms}$ and reducing the peak $\mathrm{I}_{\mathrm{Na}}$ by 5.9 and $20.1 \%$, respectively. The application of $\mathrm{Bl} \cdot \mathrm{I}_{\mathrm{Na}}$ alone produced a minor APD prolongation $(3.5 \mathrm{~ms})$ and a reduction of $16.2 \%$ in peak $\mathrm{I}_{\mathrm{Na}}$. Combining block of $\mathrm{I}_{\mathrm{Na}}$ with $\mathrm{Bl} \cdot \mathrm{I}_{\mathrm{Kur}}$ or $\mathrm{Comb} \cdot \mathrm{Bl} \cdot \mathrm{I}_{\mathrm{X}}$ promoted the genesis of AP alternans, resulting in substantial prolongations in the APD of the big APs (by $35.4 \mathrm{~ms}$ for $\mathrm{Bl} \cdot \mathrm{I}_{\mathrm{Kur}}+\mathrm{Bl} \cdot \mathrm{I}_{\mathrm{Na}}$, and $55.6 \mathrm{~ms}$ for $\mathrm{Comb} \cdot \mathrm{Bl} \cdot \mathrm{I}_{\mathrm{X}}+\mathrm{Bl} \cdot \mathrm{I}_{\mathrm{Na}}$ ) and dramatic decreases in the peak $\mathrm{I}_{\mathrm{Na}}$ (by $57.5 \%$ for $\mathrm{Bl} \cdot \mathrm{I}_{\mathrm{Kur}}+\mathrm{Bl} \cdot \mathrm{I}_{\mathrm{Na}}$ and $88.2 \%$ for Comb $\cdot \mathrm{Bl} \cdot \mathrm{I}_{\mathrm{X}}+\mathrm{Bl} \cdot \mathrm{I}_{\mathrm{Na}}$ ) in the corresponding small

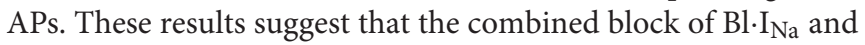
Comb $\cdot \mathrm{Bl} \cdot \mathrm{I}_{\mathrm{X}} / \mathrm{Bl} \cdot \mathrm{I}_{\text {Kur }}$ exhibited synergistic antiarrhythmic effects manifested by prolongation in APD and reduction in peak $\mathrm{I}_{\mathrm{Na}}$. However, an increased susceptibility to AP alternans was observed at a fast pacing rate of $6 \mathrm{~Hz}$, which may be potentially proarrhythmic at fast heart rates.

\section{Effects on Steady-State Restitutions of APD and Conduction Velocity}

Steady-state APD restitutions of cAF-remodeled human atria were simulated at both the cellular and tissue levels. In single myocyte simulations (Figure S5 in Online Supplementary Material 2.2), APD was prolonged over the entire range of simulated basic cycle lengths (BCL) for $\mathrm{Bl} \cdot \mathrm{I}_{\mathrm{Kur}}$ and $\mathrm{Comb} \cdot \mathrm{Bl} \cdot \mathrm{IX}_{\mathrm{X}}$ as compared to the control (drug-free) conditions. The reduction in peak $\mathrm{I}_{\mathrm{Na}}$ in $\mathrm{Bl} \cdot \mathrm{I}_{\mathrm{Na}}$ was rate-dependent and significantly greater at fast pacing rates. $\mathrm{K}^{+}$-block alone $\left(\mathrm{Bl} \cdot \mathrm{I}_{\mathrm{Kur}}\right.$ or $\mathrm{Comb} \cdot \mathrm{Bl} \cdot \mathrm{I}_{\mathrm{X}}$ ) slightly shifted the rate-dependence of peak $\mathrm{I}_{\mathrm{Na}}$ to larger BCLs. In comparison to the effects of individual current block scenarios, synergistic reductions in peak $\mathrm{I}_{\mathrm{Na}}$ were observed following combined blocks of $\mathrm{Bl} \cdot \mathrm{I}_{\mathrm{Na}}$ with $\mathrm{Bl} \cdot \mathrm{I}_{\mathrm{Kur}}$ or $\mathrm{Comb} \cdot \mathrm{Bl} \cdot \mathrm{I}_{\mathrm{X}}$ over a wide range of BCLs. As compared to the drug-free conditions, AP alternans were observed at greater BCLs after $\mathrm{K}^{+}$-block, and this was further increased by combined $\mathrm{Na}^{+}$- and $\mathrm{K}^{+}$-block (Figure S5 in Online Supplementary Material 2.2). 



FIGURE 3 | Simulated $\mathrm{AP}$ and $\mathrm{l}_{\mathrm{Na}}$ traces of $\mathrm{CAF}$-remodeled atrial myocytes and ventricular cells in response to $\mathrm{Na}^{+}$- and $\mathrm{K}^{+}$- block regimens. (Ai) $\mathrm{APs}_{\text {from }}$ cAF-remodeled atrial myocytes paced at $1 \mathrm{~Hz}$; (Aii) Time courses of corresponding $I_{\mathrm{Na}}$ during the upstroke phase. (B) Simulated time courses of AP and $\mathbf{I}_{\mathrm{Na}}$ of a ventricular cell paced at $1 \mathrm{~Hz}$. (C) Illustration of (i) APs and (ii) the corresponding time courses of I Na of a cAF-remodeled myocyte paced at $6 \mathrm{~Hz}$. In these simulations, rate constants for $I_{\mathrm{Na}}$ blocker were: $K_{\mathrm{A}}=100 \mathrm{~ms}^{-1} \cdot \mathrm{M}^{-1}, K_{\mathrm{I}}=100 \mathrm{~ms}^{-1} \cdot \mathrm{M}^{-1}, I_{\mathrm{A}}=1 \mathrm{~ms}^{-1}, I_{\mathrm{I}}=0.01 \mathrm{~ms}^{-1}$.

Using a 1D model of atrial strands, the atrial APD and conduction velocity (CV) restitutions, as well as the rate-adaptation of in-tissue upstroke velocity $\left(\mathrm{V}_{\max }\right)$, were evaluated (Figure 5). The atrial activation-recovery interval (ARI) was not affected by $\mathrm{Bl} \cdot \mathrm{I}_{\mathrm{Na}}$ alone, whereas it was substantially lengthened by $\mathrm{K}^{+}$-block as compared to control (Figure 5A). Applying $\mathrm{K}^{+}$-block alone also shifted the $\mathrm{CV}$ and $\mathrm{V}_{\max }$ restitution curves rightwards (i.e., to higher BCLs) (Figures 5B,C). These rate-adaptations of $\mathrm{V}_{\max }$ and $\mathrm{CV}$ were progressively enhanced by $\mathrm{Bl} \cdot \mathrm{I}_{\mathrm{Na}}$ and the combined block over a wide range of BCLs. Synergistically enhanced rate-dependent reductions in $\mathrm{V}_{\max }$ and $\mathrm{CV}$ were observed in response to the combined blocks. Furthermore, $\mathrm{K}^{+}$-block increased the critical BCLs for conduction block as compared to the drug-free condition (Figure 5C). 

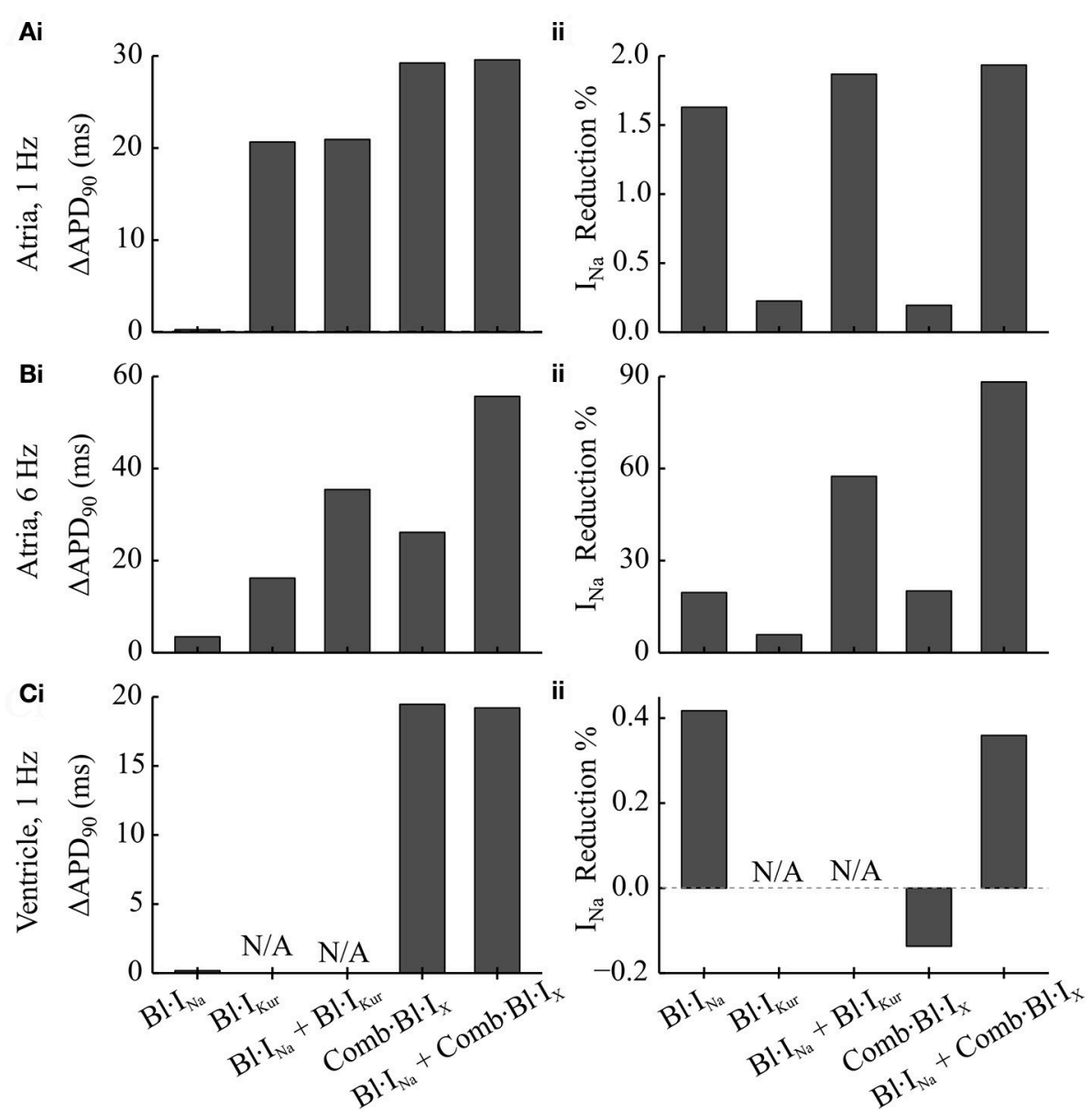

FIGURE 4 | Simulated changes in the APD and peak $I_{\mathrm{Na}}$ following the applications of $\mathrm{Na}^{+}$- and $\mathrm{K}^{+}$- block in comparison to the drug-free condition in cAF-remodeled atrial myocytes or ventricular cells. (A,B) Changes in (i) APD and (ii) peak $I_{\mathrm{Na}}$ measured from a cAF-remodeled atrial myocyte paced at (A) $1 \mathrm{~Hz}$ and (B) $6 \mathrm{~Hz}$. In the presence of alternans, the changes in APD were quantified by comparing the corresponding longer APs. The fractional reductions in peak $I_{\text {Na }}$ were calculated from the $I_{\mathrm{Na}}$ of the corresponding shorter APs. (C) Changes in (i) APD and (ii) peak $I_{\mathrm{Na}}$ measured from an in silico ventricular myocyte paced at $1 \mathrm{~Hz}$.

\section{Effects of Combined $\mathrm{Na}^{+}$- and $\mathrm{K}^{+}$- Block on the AF-Selectivity of $I_{\mathrm{Na}}$ block}

AF-selectivity of $\mathrm{Na}^{+}$blockers in cAF-remodeled hearts was examined by varying the drug binding and unbinding constants over wide parameters spaces to provide information concerning drug- $\mathrm{Na}^{+}$-channel interactions for various drug candidates. This was done by independently changing $L_{A}$ and $L_{I}$ for fixed $\left\{K_{A}, K_{I}\right\}$ (Online Supplementary Material 2.3); and then varying $K_{A}$ and $K_{I}$ for fixed $\left\{L_{A}, L_{I}\right\}$. In this way we obtained the maximum AF-selectivity over the parameter space of drug binding and unbinding kinetics. Simulations with varied $K_{A}$ and $K_{I}$ were repeated for $\mathrm{Bl} \cdot \mathrm{I}_{\mathrm{Na}}+\mathrm{Bl} \cdot \mathrm{I}_{\mathrm{Kur}}$ and $\mathrm{Bl} \cdot \mathrm{I}_{\mathrm{Na}}+\mathrm{Comb} \cdot \mathrm{Bl} \cdot \mathrm{I}_{\mathrm{X}}$.

Figures 6A-D illustrates the block efficacy (defined in Equation 4), rate-selectivity, atrial-selectivity and the resultant AF-selectivity for $\mathrm{Bl} \cdot \mathrm{I}_{\mathrm{Na}}$ alone and the combined block as a function of $K_{A}$ and $K_{I}$. For Bl- $\mathrm{I}_{\mathrm{Na}}$ alone, the block efficacy increased with increase of $K_{\mathrm{I}}$, whereas the rate-selectivity was reduced by increasing $K_{A}$ or $K_{I}$. The AF-selectivity reached a maximum value of 9 at $K_{A}=1$ and $K_{I}=500 \mathrm{~ms}^{-1} \cdot \mathrm{M}^{-1}$.
The combined blocks achieved significantly greater AF-selectivity than $\mathrm{Bl} \cdot \mathrm{I}_{\mathrm{Na}}$ alone: the maximum attainable AF-selectivity was increased by nearly 6-fold for $\mathrm{Bl} \cdot \mathrm{I}_{\mathrm{Kur}}+\mathrm{Bl} \cdot \mathrm{I}_{\mathrm{Na}}$ and more than 14 -fold for $\mathrm{Comb} \cdot \mathrm{Bl} \cdot \mathrm{I}_{\mathrm{X}}+\mathrm{Bl} \cdot \mathrm{I}_{\mathrm{Na}}$ as compared to $\mathrm{Bl} \cdot \mathrm{I}_{\mathrm{Na}}$ alone (Figure 6C). These dramatic increases were attributed to the significantly greater values in all metrics contributing to the AF-selectivity. The maximal block efficacy achieved by $\mathrm{Bl} \cdot \mathrm{I}_{\mathrm{Na}}$ alone was 0.77 , and was increased to 0.81 and 0.94 for $\mathrm{Bl} \cdot \mathrm{I}_{\mathrm{Kur}}+\mathrm{Bl} \cdot \mathrm{I}_{\mathrm{Na}}$ and $\mathrm{Comb} \cdot \mathrm{Bl} \cdot \mathrm{I}_{\mathrm{X}}+\mathrm{Bl} \cdot \mathrm{I}_{\mathrm{Na}}$, respectively. A more appreciable increase in the maximal rate-selectivity was observed by the combined blocks as compared to $\mathrm{Bl} \cdot \mathrm{I}_{\mathrm{Na}}$ alone

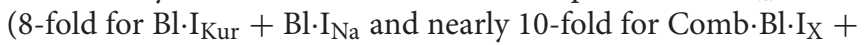
$\left.\mathrm{Bl} \cdot \mathrm{I}_{\mathrm{Na}}\right)$. Additionally, the atrial-selectivity was also increased by the combined block, although to a lesser extent. Bl- $\mathrm{I}_{\mathrm{Kur}}+\mathrm{Bl} \cdot \mathrm{I}_{\mathrm{Na}}$ exhibited a greater atrial-selectivity than that of Comb $\cdot \mathrm{Bl} \cdot \mathrm{I}_{\mathrm{X}}$ $+\mathrm{Bl} \cdot \mathrm{I}_{\mathrm{Na}}$ since $\mathrm{Bl} \cdot \mathrm{I}_{\mathrm{Kur}}$ was assumed to have no effect on the ventricles.

Furthermore, these simulations revealed that the block efficacy, rate-selectivity and atrial-selectivity were strongly 


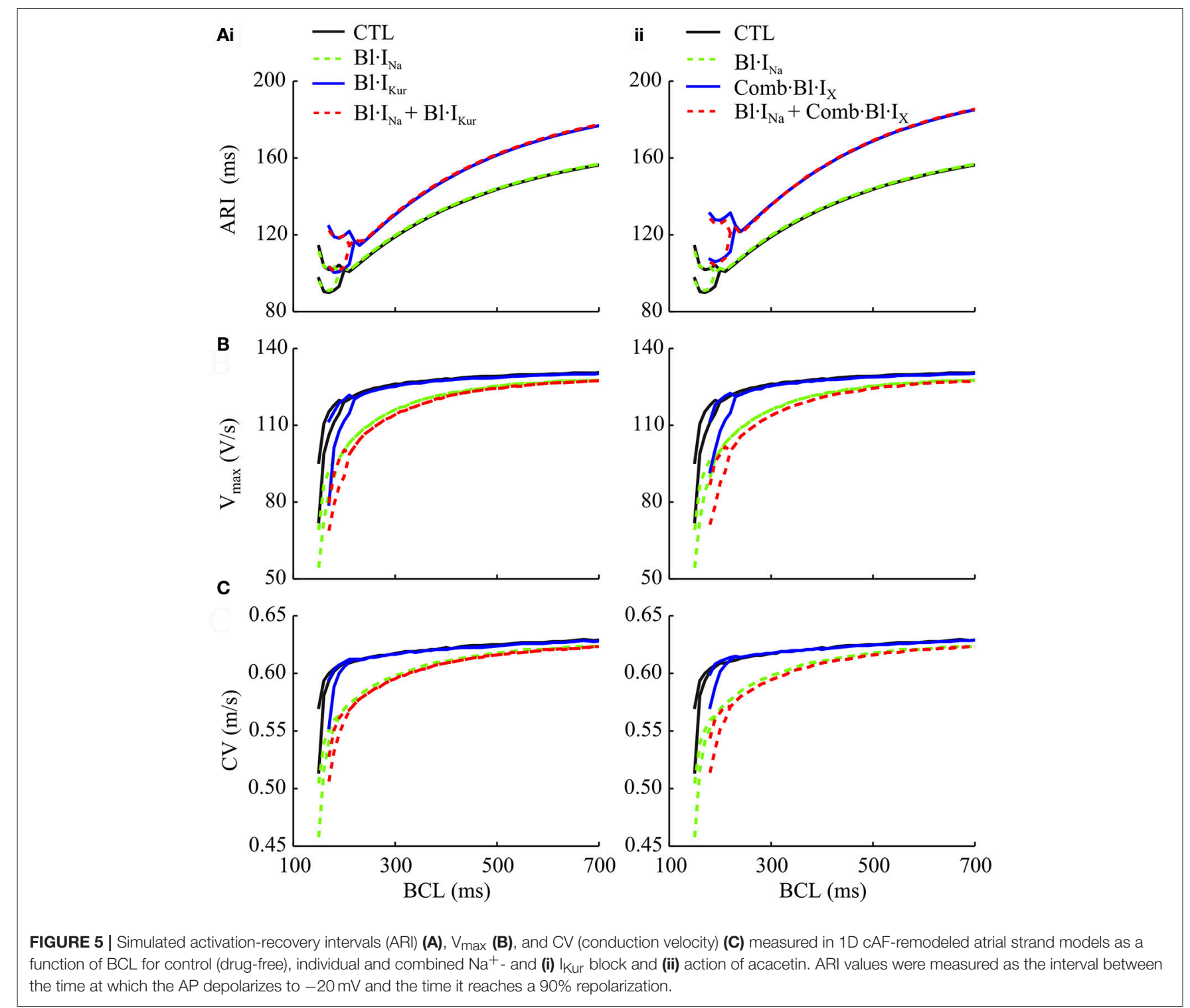

dependent on the inactivation state binding rate $K_{I}$. These measures were also dependent on the open-state binding kinetics $K_{A}$, but to a much lesser extent. The block efficacy was mainly determined by $K_{I}$ : an increase in $K_{I}$ led to a significant increase in the block efficacy. In combined block, the maximal rate- and atrial-selectivity were observed for $K_{A}=K_{I}=1 \mathrm{~ms}^{-1}$. $\mathrm{M}^{-1}$ and increases in $K_{I}$ resulted in substantial reductions in the rate- and atrial-selectivity. In $\mathrm{Bl} \cdot \mathrm{I}_{\mathrm{Na}}$ alone, the parameter set $K_{A}=1 \mathrm{~ms}^{-1} \cdot \mathrm{M}^{-1}, K_{I}=200 \mathrm{~ms}^{-1} \cdot \mathrm{M}^{-1}$ produced a maximal value in atrial-selectivity. Collectively, the optimal $K_{I}$ that maximized AF-selectivity was $200 \mathrm{~ms}^{-1} \cdot \mathrm{M}^{-1}$ for $\mathrm{Bl} \cdot \mathrm{I}_{\mathrm{Na}}$ and $\mathrm{Bl} \cdot \mathrm{I}_{\mathrm{Kur}}+\mathrm{Bl} \cdot \mathrm{I}_{\mathrm{Na}}$, and smaller $\left(100 \mathrm{~ms}^{-1} \cdot \mathrm{M}^{-1}\right)$ for Comb $\cdot \mathrm{Bl} \cdot \mathrm{IX}_{\mathrm{X}}+\mathrm{Bl} \cdot \mathrm{I}_{\mathrm{Na}}$. The optimal $K_{A}=1 \mathrm{~ms}^{-1} \cdot \mathrm{M}^{-1}$ was seen for all conditions. Increasing $K_{A}$ consistently resulted in a smaller rate- and atrial-selectivity and therefore reduced AF-selectivity. These results suggest that the inactivation-state binding rate might be a more favorable targeting parameter than the open-state binding kinetics in optimizing AF-selectivity of $\mathrm{Na}^{+}$-blockers.

\section{Effects of $I_{\mathrm{Na}}$ and $I_{\mathrm{Kur}}$ Block on Spiral Excitation Events in cAF-Remodeled Atria} Two-Dimensional Simulations

Using the cross-shock protocol, spiral waves were initiated in a 2D model representing a tissue slab of cAF-remodeled human atria. For each condition, a 10-s episode of electrical activity was simulated. Representative snapshots of the re-entrant waves in control (drug-free) and following application of drugs are presented in Figure 7A. The trajectories of the tips of re-entrant rotors under these conditions were traced and are shown in Figure $7 \mathbf{B}$. The number of rotors during the time course of wave evolution was also measured (Figure 7C). The simulated pseudoECGs, membrane potential traces extracted from a representative 


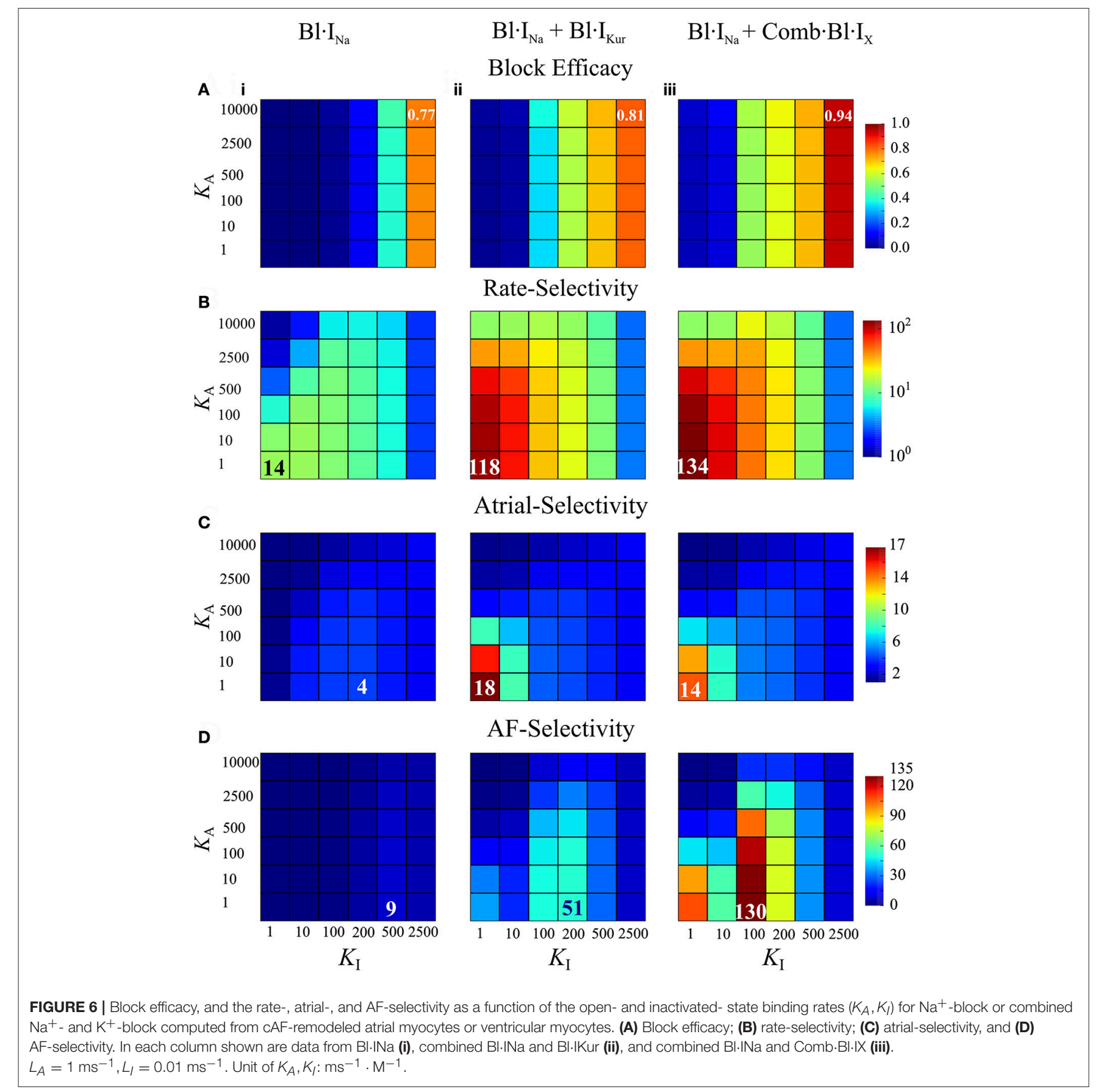

myocyte and the corresponding fractional block of $\mathrm{I}_{\mathrm{Na}}$ and $\mathrm{I}_{\mathrm{Kur}}$ are detailed in Online Supplementary Material 2.4.

Under the control (drug-free) condition, a single rotor was formed at approximately $t=630 \mathrm{~ms}$; this broke into two spiral waves at $t=830 \mathrm{~ms}$. These two rotors were stably anchored with star-shaped tip trajectories at the bottom half of the slab and persisted throughout the rest of the simulated 10-s episode (Figures 7Ai,Bi,C). In simulating drug actions, each drug was applied at $t=2,500 \mathrm{~ms}$. For $\mathrm{Bl} \cdot \mathrm{I}_{\mathrm{Na}}$ the dual rotors progressively became unstable, and the tips of the spiral waves meandered out of the tissue at approximately $t=6,000 \mathrm{~ms}$, leading to selftermination of the re-entrant waves (Figures 7Aii,Bii,C). The dual rotors persisted throughout the period of the simulation after applying $\mathrm{Bl} \cdot \mathrm{I}_{\mathrm{Kur}}$ alone (Figures 7 Aiii,Biii,C). For $\mathrm{Bl} \cdot \mathrm{I}_{\mathrm{Na}}+$ $\mathrm{Bl} \cdot \mathrm{I}_{\mathrm{Kur}}$, the rotor at the bottom left corner of the slab became unstable and meandered out of the tissue at approximately $t$ $=3,800 \mathrm{~ms}$, whereas the trajectory of the second rotor was confined to a small tissue area until $t=7,000 \mathrm{~ms}$ and then gradually became chaotic, forming up to 3 transient rotors that self-terminated at $t=8,334 \mathrm{~ms}$ (Figures 7Aiv,Biv,C). A 


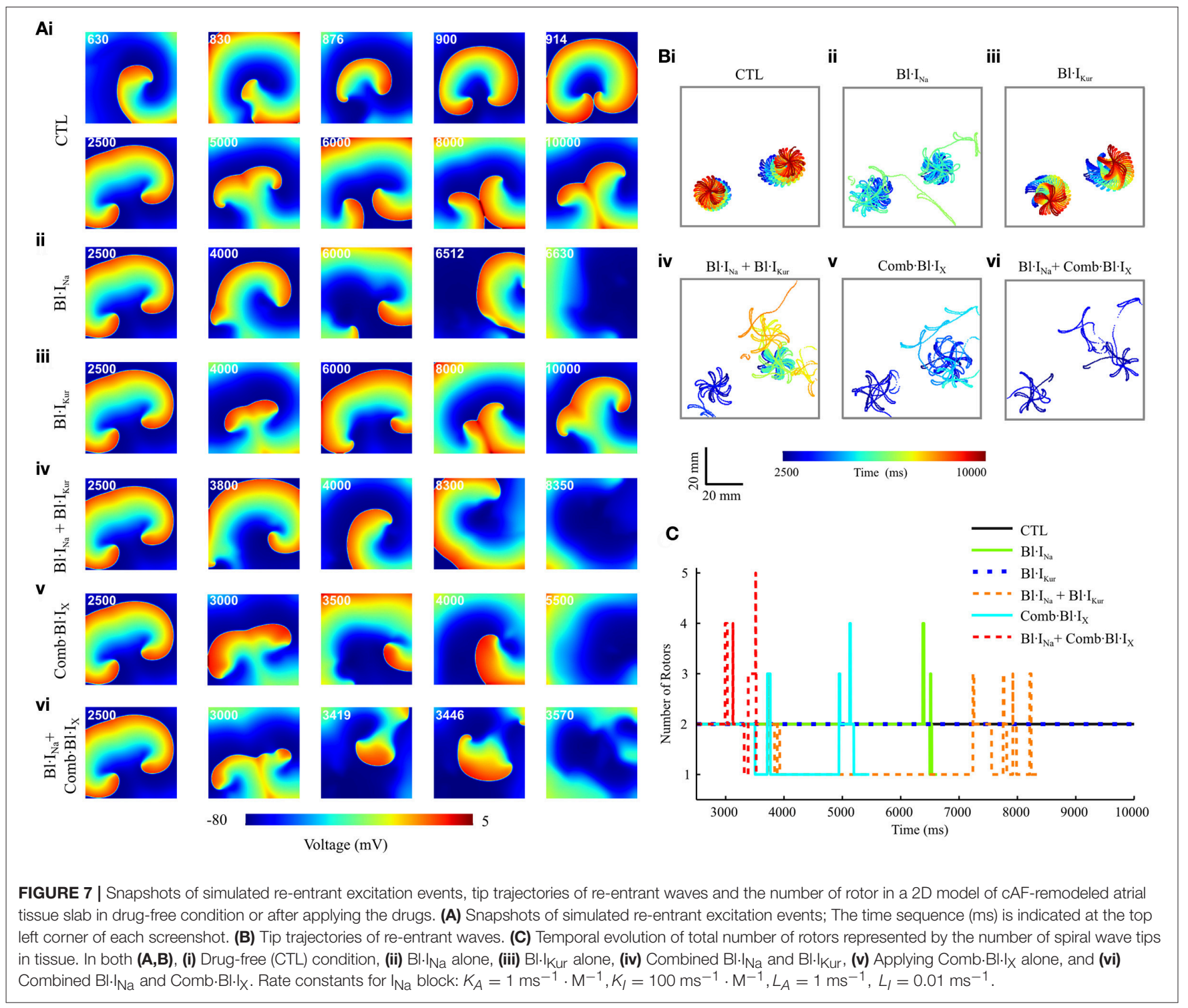

similar but more marked effect was seen in the simulations that addressed the aggregate effects of acacetin: the bottom left rotor quickly meandered out of the tissue at $t=3,510 \mathrm{~ms}$ whilst the tip trajectory of the other rotor became chaotic and terminated at $t=5,439 \mathrm{~ms}$ (Figures $7 \mathbf{A v}, \mathbf{B v}, \mathbf{C}$ ). We note that the combined Bl. $\mathrm{I}_{\mathrm{Na}}$ and Comb $\cdot \mathrm{Bl} \cdot \mathrm{I}_{\mathrm{X}}$ exerted the strongest potency in terminating re-entrant excitations in these simulations: the two rotors transiently turned unstable and chaotic and selfterminated at $t=3,555 \mathrm{~ms}$, with up to 5 rotors during the excitation in the slab (Figures 7Avi,Bvi,C).

The anti-arrhythmic benefits of combined $\mathrm{Na}^{+}$- and $\mathrm{K}^{+}$block were clearly revealed by additional simulations assuming the use of a different $\mathrm{Na}^{+}$-blocker $\left(K_{A}=1 \mathrm{~ms}^{-1} \cdot \mathrm{M}^{-1}, K_{I}=\right.$ $\left.200 \mathrm{~ms}^{-1} \cdot \mathrm{M}^{-1}, L_{A}=1 \mathrm{~ms}^{-1}, L_{I}=0.01 \mathrm{~ms}^{-1}\right)$ and at a reduced dose $(75 \%)$ of both $\mathrm{Na}^{+}$-blocker and acacetin. The life span of reentrant excitations was measured and shown in Figure 8A. Also, the pECG was computed and the segment from $t=3,000 \mathrm{~ms}$ to
$500 \mathrm{~ms}$ before the termination of re-entries (or the end of the simulation if the rotor sustained) was analyzed using the Fast Fourier Transform to obtain the dominant frequency (DF) of the re-entrant excitations, which is illustrated in Figure 8B.

At the simulated doses of acacetin, applying $\mathrm{Bl} \cdot \mathrm{I}_{\mathrm{Kur}}$ alone did not lead to termination of re-entrant waves within the duration of the simulation (7,500 $\mathrm{ms}$ after $\mathrm{T}_{\text {Drug }}$ ), whereas the rotors were terminated in the simulations for Comb-Bl. IX at both doses (Figure 8Ai-iv), thus demonstrating enhanced anti-AF benefits of combined $\mathrm{K}^{+}$-channel block. For the simulated $\mathrm{Bl} \cdot \mathrm{I}_{\mathrm{Na}}$ alone, the $\mathrm{Na}^{+}$-blocker with $K_{I}=100 \mathrm{~ms}^{-1} \cdot \mathrm{M}^{-1}$ led to termination of AF at the control dose (lifespan of 4,102 ms) but not at the reduced dose; increasing $K_{I}$ of the $\mathrm{Na}^{+}$-blocker to $200 \mathrm{~ms}^{-1} \cdot \mathrm{M}^{-1}$ resulted in a reduced lifespan $\left(1,305\right.$ and $1,459 \mathrm{~ms}$ for $\left[D_{\mathrm{Na}^{+}}\right]=$ 60 and $45 \mu \mathrm{M}$, respectively). The lifespan for the combined $\mathrm{Bl} \cdot \mathrm{I}_{\mathrm{Na}}+\mathrm{Comb} \cdot \mathrm{Bl} \cdot \mathrm{I}_{\mathrm{X}}$ was consistently shorter than that of any individual applications of $\mathrm{Bl} \cdot \mathrm{I}_{\mathrm{Na}}$ or $\mathrm{Comb} \cdot \mathrm{Bl} \cdot \mathrm{I}_{\mathrm{X}}$ alone in all cases. 
A similar augmented anti-arrhythmic effect (shown as shortened lifespan of re-entry) was also observed for the combined $\mathrm{Bl} \cdot \mathrm{I}_{\mathrm{Na}}$ $+\mathrm{Bl} \cdot \mathrm{I}_{\mathrm{Kur}}$ for $\left[D_{\mathrm{Na}^{+}}\right]=45 \mu \mathrm{M}$ and $K_{I}=200 \mathrm{~ms}^{-1} \cdot \mathrm{M}^{-1}$

(Figure 8Aiv) but not for the rest of the cases.

A consistent decrease in the DF was observed in the drugmodulated re-entrant excitations as compared to those in the drug-free condition (Figure $\mathbf{8 B i}$-iv). In the drug-free condition, the DF extracted from the pECG was $8.63 \mathrm{~Hz}$, which is within the range of similar clinical data (Jarman et al., 2012). Applying $\mathrm{Na}^{+}$- or $\mathrm{K}^{+}$- block individually resulted in slowing of the rate of the rotors, and this was dependent on the concentrations and parameters of the blockers. For Bl- $\mathrm{I}_{\text {Kur }}$ the DF was $8.25 \mathrm{~Hz}$

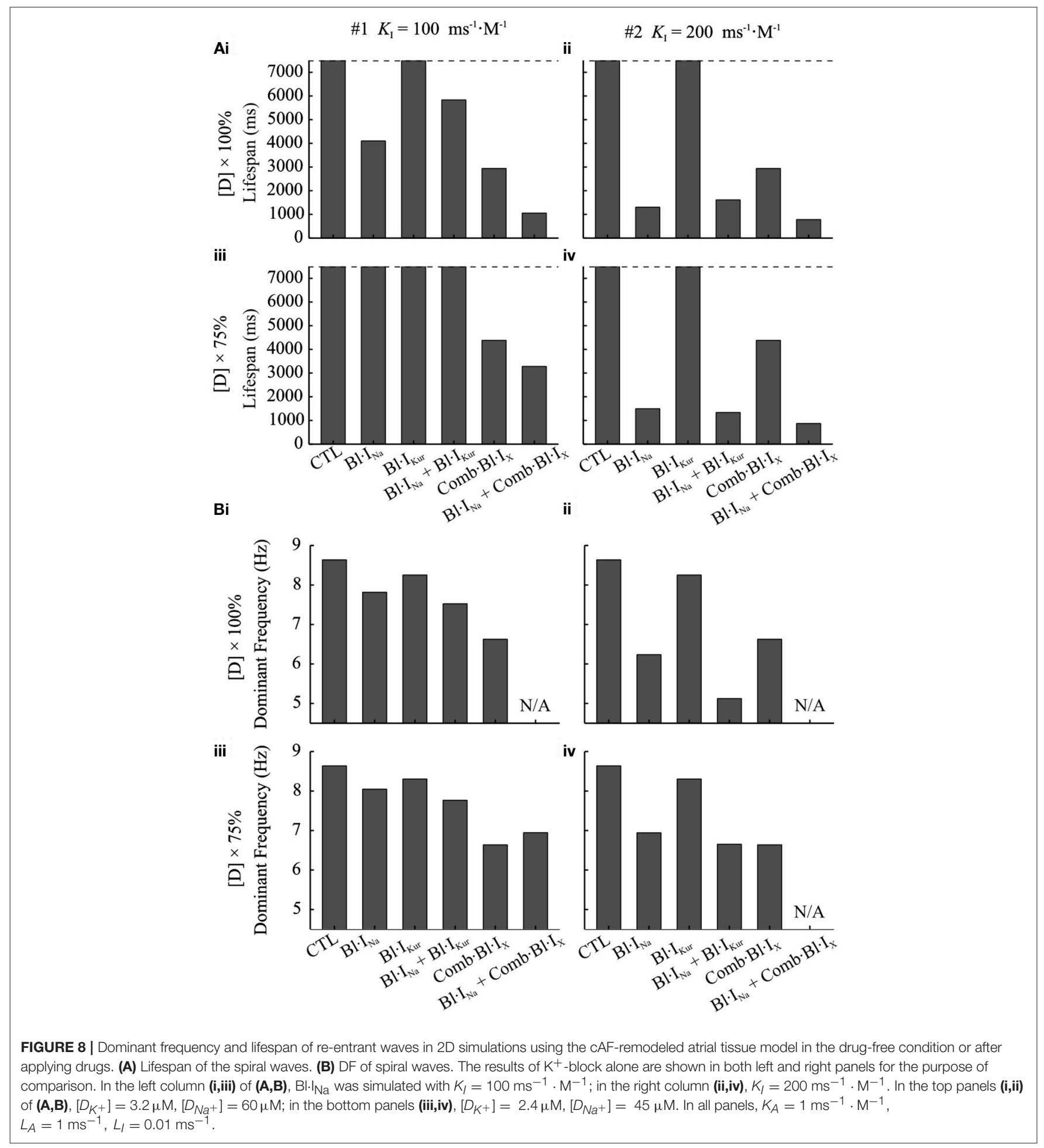


with the control dose and $8.30 \mathrm{~Hz}$ for the reduced dose. In the simulations with Comb $\cdot \mathrm{Bl} \cdot \mathrm{I}_{\mathrm{X}}$, the DF was $6.63 \mathrm{~Hz}$ and was not affected by the $25 \%$ reduction in the dose of the compound. For $\mathrm{Bl} \cdot \mathrm{I}_{\mathrm{Na}}$ alone the $\mathrm{DF}$ was $7.81 \mathrm{~Hz}$ and substantially smaller $(6.24 \mathrm{~Hz})$ for $\mathrm{Na}^{+}$-blockers of $K_{I}=100 \mathrm{~ms}^{-1} \cdot \mathrm{M}^{-1}$ and $K_{I}=$ $200 \mathrm{~ms}^{-1} \cdot \mathrm{M}^{-1}$, respectively. An enhanced deceleration of the rotors was observed for $\mathrm{Bl} \cdot \mathrm{I}_{\mathrm{Na}}+\mathrm{Bl} \cdot \mathrm{I}_{\mathrm{Kur}}$ in all cases. The $\mathrm{DF}$ for simulations with $\mathrm{Comb} \cdot \mathrm{Bl} \cdot \mathrm{I}_{\mathrm{X}}+\mathrm{Bl} \cdot \mathrm{I}_{\mathrm{Na}}$ was not computed due to the short lifespan in these events.

\section{D Simulations}

The antiarrhythmic effects of acacetin and $\mathrm{Na}^{+}$-block on the reentrant waves in the cAF-remodeled atria were also evaluated using our 3D anatomical model of the human atria (Colman et al., 2013, 2017). A 10-s episode of sustained re-entrant excitation was first initiated in the cAF-remodeled atria in the drugfree condition; this produced the initial conditions of the $3 \mathrm{D}$ model for additional 10-s episode simulations. Next, the behavior of electrical waves of another 10-s episode simulation in the drug-free condition and after applying the selected blockers was analyzed and compared. Figure 9A shows snapshots of excitation wave evolution following the 10-s episode of re-entrant excitation events. pECGs computed from the excitation waves are shown in Figure 9Bi-iv. Figures 9C,D illustrates power spectrum analyses of the pECGs and a comparison of the lifespan of the electrical waves in the drug-free condition and after applying the drugs/blockers. In the drug-free condition, stable reentrant waves around the pulmonary veins and left atrium were observed; the power spectrum density (PSD) manifests a singlefocused peak around $8.16 \mathrm{~Hz}$. Following applying $\mathrm{Bl} \cdot \mathrm{I}_{\mathrm{Na}}$, the reentrant waves became less organized and also decelerated. This was characterized by a smaller dominant frequency $(6.58 \mathrm{~Hz})$ and less focused PSD distribution; the excitation was not terminated. Following the application of Comb $\cdot \mathrm{Bl} \cdot \mathrm{I}_{\mathrm{X}}$, the re-entrant wave soon became unstable and eventually disappeared after $t=$ $3,279 \mathrm{~ms}$. Note that the peak PSD amplitude was much smaller and its distribution was much broader as compared to the drug-free condition. The combined drugs further destabilized the re-entrant waves and reduced the lifespan to approximately $1,120 \mathrm{~ms}$.

\section{Simulated Effects of Acacetin and $\mathrm{Na}^{+}$-Current Blocker on the QT Interval}

Further simulations were performed using a $1 \mathrm{D}$ ventricular transmural strand model to evaluate the changes in the waveform of electrograms in consequence of applying the drugs. A comparison of the computed electrogram waveforms are illustrated in Figures 10A,B, and the QT intervals are quantified in Figure 10C. Blocking small fractions of $\mathrm{I}_{\mathrm{Kr}}, \mathrm{I}_{\mathrm{Ks}}$ and $\mathrm{I}_{\text {to }}$ in the human ventricles by acacetin slightly increased the QT interval by $21 \mathrm{~ms}$. The electrograms were not noticeably affected by applications of the $\mathrm{Na}^{+}$-blocker with the simulated parameters. Results from both cases did not show dramatic QT prolongation, indicating no dramatic effects affecting ventricular repolarization process which might promote ventricular arrhythmias.

\section{DISCUSSION}

Even decades after goal-directed work, successful development of effective and safe antiarrhythmic drugs for treating AF has not been accomplished and remains a major unmet clinical need. In a recent study on the canine heart, enhanced anti-arrhythmic effects and AF-selectivity of $\mathrm{I}_{\mathrm{Na}}$ blockade by additional $\mathrm{I}_{\mathrm{Kur}}$ block was demonstrated (Aguilar et al., 2015). Whether similar effects could be obtained in the human atria, especially following cAF-induced electrical remodeling which reduces $\mathrm{I}_{\mathrm{Kur}}$, remained unclear. How the combined $\mathrm{Na}^{+}$and $\mathrm{K}^{+}$-block modulates the QT interval also remained incompletely understood. In this study, the effects of $\mathrm{I}_{\mathrm{Kur}}$ (combined with a modest block in $\mathrm{I}_{\mathrm{to}}$, $\mathrm{I}_{\mathrm{Kr}}$, and $\mathrm{I}_{\mathrm{Ks}}$ as presented by acacetin, a compound shown to be effective in anti-AF treatment) and $\mathrm{I}_{\mathrm{Na}}$ block (two potentially effective atrial-selective block on human atrial electrophysiology) were investigated in silico using multiscale models of the human atria and state-dependent block scheme. The simulation results demonstrate that both $\mathrm{Na}^{+}$-block and $\mathrm{K}^{+}$-block exhibited anti-arrhythmic effects in the atria following cAF-remodeling, despite reduced $\mathrm{I}_{\mathrm{Kur}}$ by the remodeling. The present study highlighted that in addition to combined $\mathrm{Na}^{+}$- and $\mathrm{K}^{+}$-block, combined multi- $\mathrm{K}^{+}$-channels also exerted beneficial synergistic antiarrhythmic effects when compared with single channel block whilst having modest impact on ventricular repolarization (QT interval). This study suggests that multi-channel block (either combined $\mathrm{Na}^{+}-\mathrm{K}^{+}$-block, or combined multi-K $\mathrm{K}^{+}$-block) may be a favorable strategy for the development of novel pharmaceutical therapies for AF.

\section{Effects of $I_{\mathrm{Na}}$ block}

An atrial-ventricular difference in the properties of $\mathrm{I}_{\mathrm{Na}}$, especially in the voltage dependence of steady-state inactivation, has been reported (Li et al., 2002; Burashnikov et al., 2007; Chen et al., 2016; Fan et al., 2016; Caves et al., 2017). In these studies, the voltage dependent steady-state inactivation curves for $\mathrm{I}_{\mathrm{Na}}$ were found to be negatively shifted (by $5-16 \mathrm{mV}$ ) in atrium as compared to the ventricular parameters. This difference gave rise to an on-going interest in developing an atrial-selective blocker of $\mathrm{I}_{\mathrm{Na}}$ as a strategy in terminating AF (Burashnikov et al., 2007; Antzelevitch and Burashnikov, 2009; Zygmunt et al., 2011; Morotti et al., 2016; Caves et al., 2017). As was done in previous studies (Aguilar-Shardonofsky et al., 2012; Aguilar et al., 2015), in this study, the kinetic parameters in drug actions of $\mathrm{Na}^{+}$blockers were varied over wide parameter spaces to reveal AFselectivity of $\mathrm{Na}^{+}$-blockers in the ventricles and fibrillating atria. Our results demonstrated that in the presence of AF-remodeling, an atrial-selective block of $\mathrm{I}_{\mathrm{Na}}$ could produce different effects between atrial and ventricular cells (Figures 3, 4) and that the AF-selectivity could be maximized by optimizing the binding and unbinding rates of the $\mathrm{Na}^{+}$-blocker (Figure 6). Note also that, the fractional inhibition of $\mathrm{I}_{\mathrm{Na}}$ by the $\mathrm{Na}^{+}$-blocker exhibited a substantial dependence on the rate of pacing (Figures 3, 4 and Online Supplementary Material 2.2), which was quantified using the rate-selectivity (Figure 6).

At the cellular level, $\mathrm{Na}^{+}$-block resulted in a significant inhibition in $\mathrm{I}_{\mathrm{Na}}$ at fast pacing rates, but minor effects within 


\section{A}

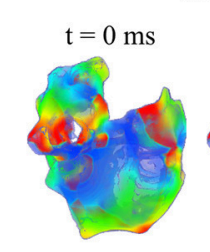

CTL


$\mathrm{B} 1 \cdot \mathrm{I}_{\mathrm{Na}}$
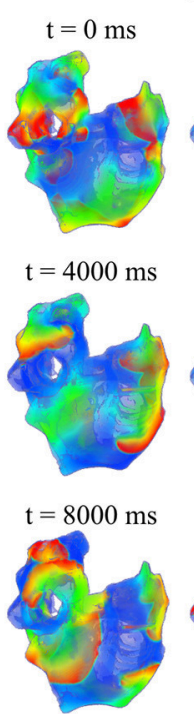

$\mathrm{Comb} \cdot \mathrm{Bl} \cdot \mathrm{I}_{\mathrm{X}}$

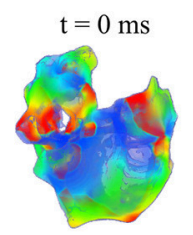

$\mathrm{t}=6000 \mathrm{~ms}$



$\mathrm{t}=10000 \mathrm{~ms}$

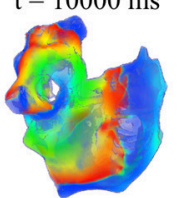



$\mathrm{t}=1300 \mathrm{~ms}$

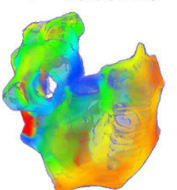

$\mathrm{t}=1950 \mathrm{~ms}$
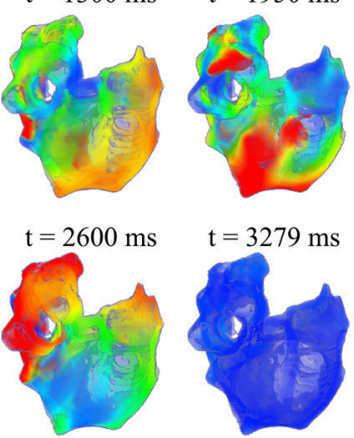

$-83$

Membrane Voltage $(\mathrm{mV})$

10

$\mathrm{Bl} \cdot \mathrm{I}_{\mathrm{Na}}+\mathrm{Comb} \cdot \mathrm{Bl} \cdot \mathrm{I}_{\mathrm{X}}$
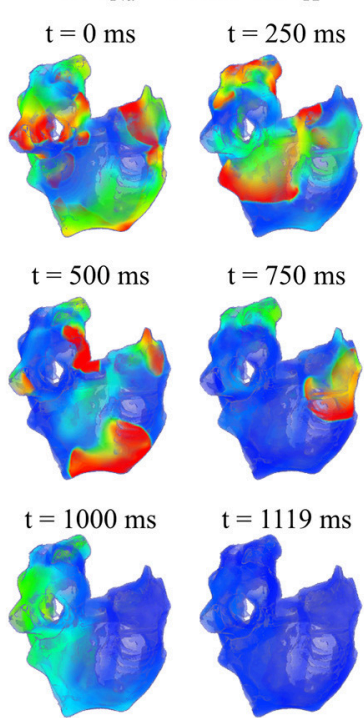

Bi

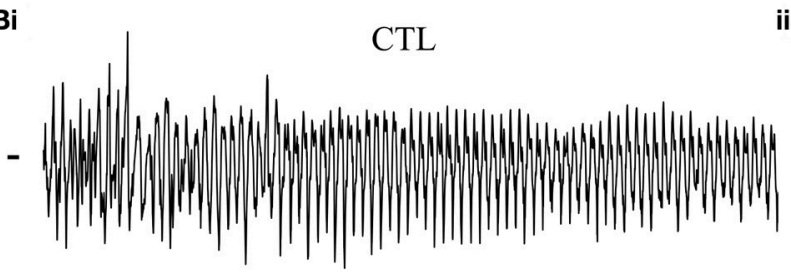

ii

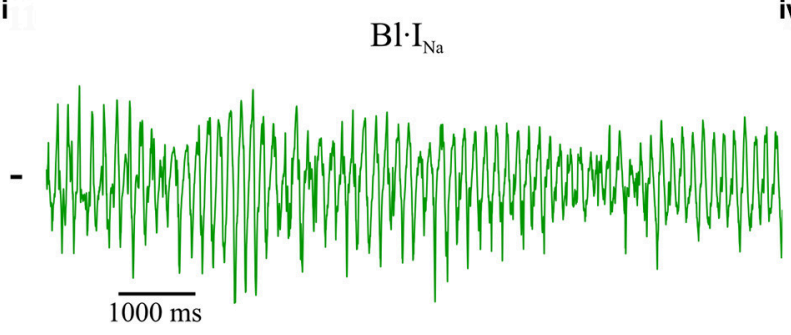

iii

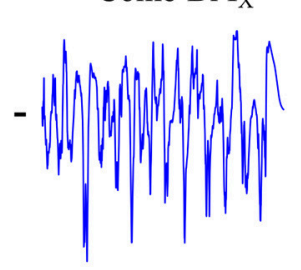

iv

C

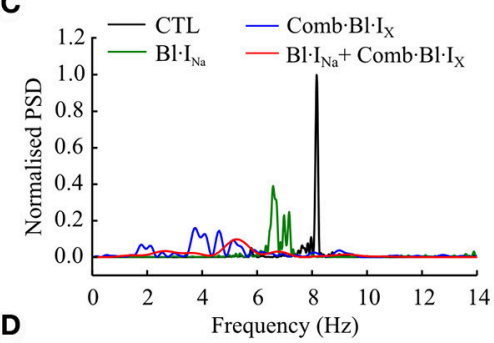

$\mathrm{B} 1 \cdot \mathrm{I}_{\mathrm{Na}}+\mathrm{Comb} \cdot \mathrm{Bl} \cdot \mathrm{I}_{\mathrm{X}}$

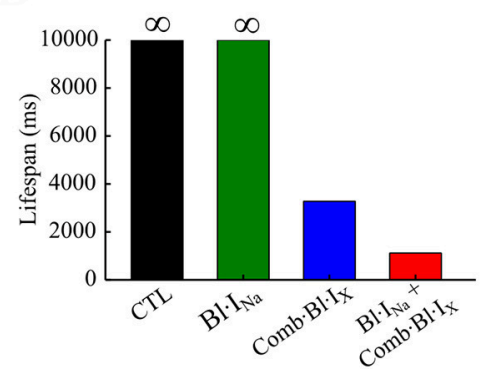

FIGURE 9 | Simulated re-entrant excitations computed using the 3D anatomical model of the cAF-remodeled human atria in response to application of channel blockers as compared to that of the drug-free (CTL) condition. (A) Snapshots of electrical excitation waves. Drugs were applied at $t=0$ ms. (B) Simulated pECGs. (C) Power spectrum density (PSD) obtained from the pECGs. PSDs were normalized to the maximum value of that in control. (D) Lifespan of re-entrant excitations in these simulated atria for various conditions. The symbol $\infty$ indicates the spiral waves were sustained throughout the 10-s episode of simulation. $K_{A}=1 \mathrm{~ms}^{-1} \cdot \mathrm{M}^{-1}, K_{l}=100 \mathrm{~ms}^{-1} \cdot \mathrm{M}^{-1}, L_{A}=1 \mathrm{~ms}^{-1}, L_{l}=0.01 \mathrm{~ms}^{-1} ;\left[D_{K^{+}}\right]=3.2 \mu \mathrm{M},\left[D_{\mathrm{Na}^{+}}\right]=60 \mu \mathrm{M}$.

the range of normal heart rates in the atria (Figures 5, 6). The antiarrhythmic effects of these changes were demonstrated in simulations of multicellular atrial tissue. In a $1 \mathrm{D}$ atrial strand model, applying $\mathrm{Na}^{+}$-block progressively enhanced the rateadaptations of $\mathrm{V}_{\max }$ and $\mathrm{CV}$ over a larger range of BCLs, whereas the atrial APD was not affected. At fast pacing rates, $V_{\max }$ and $\mathrm{CV}$ were decreased significantly, suggesting reduced excitabilities of atrial myocytes (Figure 5). These results are in concordance with the recent study (Aguilar et al., 2015) where similar effects of $\mathrm{Na}^{+}$-block on the canine atria were demonstrated in silico and experimentally in coronary-perfused hearts.

In $2 \mathrm{D}$ tissue simulations, this $\mathrm{Na}^{+}$-block shortened the lifespan and caused slowing in the excitation rate of the spiral waves (Figures 7, 8). In the 3D anatomical model, applying $\mathrm{Na}^{+}$-block alone produced antiarrhythmic effects by slowing the re-entrant excitations (Figure 9). Furthermore, 
A

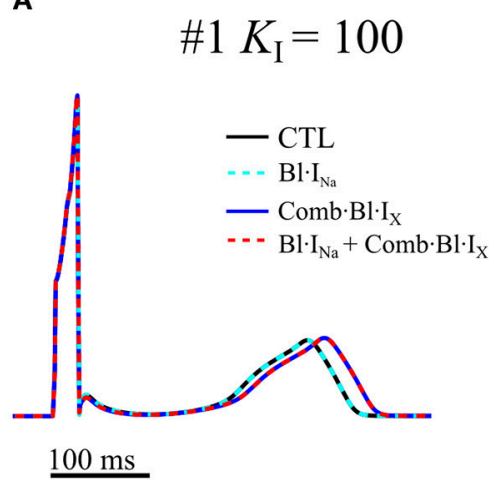

B

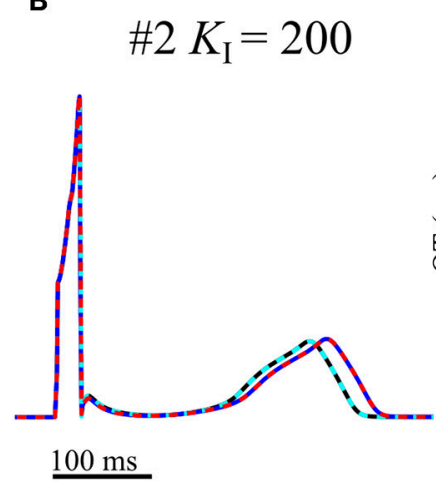

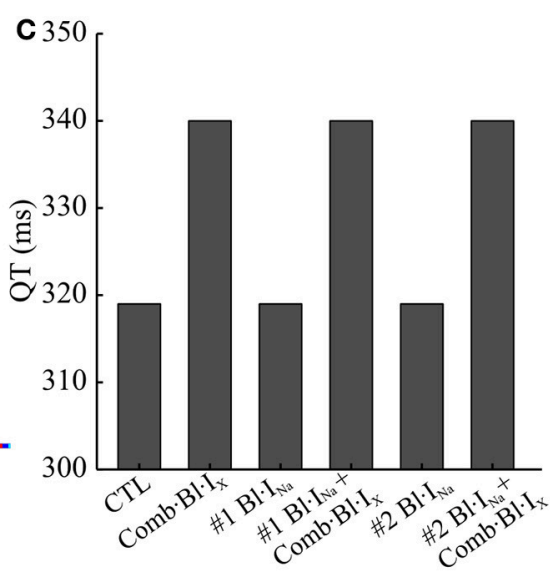

FIGURE 10 | Computed pECGs from a 1D strand model for human ventricular transmural strands in drug-free (CTL) condition and in response to anti-arrhythmic drugs. In (A,B) two sets of parameters (\#1 $K_{I}=100 \mathrm{~ms}^{-1} \cdot \mathrm{M}^{-1}$, \#2 $K_{\mathrm{I}}=200 \mathrm{~ms}^{-1} \cdot \mathrm{M}^{-1}$ ) for $\mathrm{I}_{\mathrm{Na}}$ block were simulated. (C) QT intervals measured from the pECGs.

in our $1 \mathrm{D}$ model of transmural ventricular strand, the simulations suggested that the $\mathrm{Na}^{+}$-block had minimal impact on ventricular repolarization, as judged by modest QT interval prolongation. These results demonstrated that $\mathrm{Na}^{+}$-block could be beneficial in suppressing re-entrant activities in the cAF-remodeled atria, with modest impact on ventricular repolarization.

\section{Effects of $\mathrm{K}^{+}$-Current Block}

$\mathrm{K}^{+}$-current blockers delay the repolarization phase of the AP and thus prolong atrial APD and refractory period. This can cause disruptions and eventually termination of the re-entrant circuits (Hancox et al., 2016). However, $\mathrm{K}^{+}$-channel blockers such as dofetilide and sotalol (which potently inhibit $\mathrm{I}_{\mathrm{Kr}}$ ) have a substantial risk of prolonging QT interval and promoting Torsades de pointes arrhythmias (Hondeghem and Snyders, 1990; Yap and Camm, 2003). In principle, blocking atrial-specific $\mathrm{K}^{+}$channels may exert antiarrhythmic effects in the atria while minimizing potential risks of adverse effects in the ventricles. $\mathrm{I}_{\text {Kur }}$ is believed to be such an atrial-selective substrate for drug interventions, and effects of $\mathrm{I}_{\mathrm{Kur}}$ block have been extensively studied (Burashnikov and Antzelevitch, 2008; Li et al., 2008; Tsujimae et al., 2008; Almquist et al., 2010; Pavri et al., 2012; Scholz et al., 2013; Loose et al., 2014; Ford et al., 2016). Interestingly, many existing $\mathrm{I}_{\mathrm{Kur}}$ blockers potently block other $\mathrm{K}^{+}$-channels including $\mathrm{I}_{\text {to }}$ and $\mathrm{I}_{\mathrm{K}, \mathrm{ACh}}$ (Gögelein et al., 2004; Wirth et al., 2007; Burashnikov and Antzelevitch, 2008; Li et al., 2008). The additional blockades of these channels may contribute to the antiarrhythmic effects of those drugs, which warrant further investigations.

In this study, acacetin, a compound initially isolated from the traditional Chinese medicine Xuelianhua, was selected as a representative $I_{K u r}$ blocker. The effects of acacetin on atrial electrophysiology were evaluated in two ways: (a) the effects of acacetin blocking $\mathrm{I}_{\mathrm{Kur}}$ only; and (b) the full actions of acacetin on the targeting channels ( $\mathrm{I}_{\mathrm{to}}, \mathrm{I}_{\mathrm{Kur}}, \mathrm{I}_{\mathrm{Kr}}$, and $\mathrm{I}_{\mathrm{Ks}}$ ) (Li et al., 2008). This approach allowed for investigations into the effects of $\mathrm{I}_{\mathrm{Kur}}$ block alone as well as the potential benefits of additional-but-modest inhibition of other $\mathrm{K}^{+}$-currents in the human atria.

\section{Selective $I_{\text {Kur }}$ Block}

Blocking $\mathrm{I}_{\mathrm{Kur}}$ with $3.2 \mu \mathrm{M}$ acacetin exerted APD prolongation $(9.8 \mathrm{~ms})$ under the baseline/normal conditions (Figure 2). Experimental data show that dependent on the baseline AP waveform the effect of $\mathrm{I}_{\mathrm{Kur}}$ block on human atrial $\mathrm{APD}_{70-90}$ under normal (SR) conditions can manifest as prolongation or shortening in the APD, (Workman et al., 2001; Wettwer et al., 2004; Schotten et al., 2007; Burashnikov and Antzelevitch, 2008; Loose et al., 2014). Additionally, the prolongation in APD by $I_{\text {Kur }}$ block observed in the present study is similar to our previous paper (Colman et al., 2017) concerning the effects of genetically down-regulated $\mathrm{I}_{\mathrm{Kur}}$. Moreover, inhibiting $\mathrm{I}_{\mathrm{Kur}}$ under normal conditions elevated the AP plateau potential and prolonged $\mathrm{APD}_{30}$ (Figure 2). Both effects matched well with experimental studies (Workman et al., 2001; Wettwer et al., 2004; Schotten et al., 2007; Burashnikov and Antzelevitch, 2008; Loose et al., 2014) and our simulation study (Colman et al., 2017).

We note that in the CAF-remodeling cells, a more pronounced prolongation in APD (by $23.6 \mathrm{~ms}$ for $1 \mathrm{~Hz}$ and $16.2 \mathrm{~ms}$ at $6 \mathrm{~Hz}$, Figure 4) was observed in the presence of $3.2 \mu \mathrm{M}$ acacetin, despite that this current was down-regulated by cAF-remodeling (Wagoner et al., 1997; Brandt et al., 2000; Christ et al., 2008). These results are in accordance with previous experimental results of blocking $\mathrm{I}_{\mathrm{Kur}}$ with MK-0448 (Pavri et al., 2012; Loose et al., 2014). In addition, $I_{\text {Kur }}$ block exhibited enhanced ratedependent adaptations in APD both at the cellular (Online Supplementary Material 2.2) and 1D strand models (Figure 5). Importantly, the $\mathrm{CV}$ restitution curve shifted toward higher BCLs, indicating that this tissue is less capable of conduction of atrial excitation waves at high rate while maintaining conduction of slow waves (Figure 5). In 2D tissue simulations, applying $\mathrm{I}_{\mathrm{Kur}}$ block alone $(3.2 \mu \mathrm{M}$ acacetin) destabilized the cores of rotors (i.e., potential organizing centers for AF), and slightly slowed their excitation rates, but failed to terminate them (Figure 7), suggesting a limited efficacy of terminating $\mathrm{AF}$ by $\mathrm{I}_{\mathrm{Kur}}$ block 
alone. Similarly, a recent modeling study by Aguilar et al. (2017) suggested that the antiarrhythmic efficacy of $\mathrm{I}_{\mathrm{Kur}}$ block was substantially decreased in the presence of AF-induced electrical remodeling. Also, the experimental study (Burashnikov and Antzelevitch, 2008) showed that block of IKur by 4-AP of small doses had limited efficacy in suppressing AF in canine atria. This may represent the fact that $\mathrm{I}_{\mathrm{Kur}}$ is reduced at high frequencies (as discussed/suggested in Feng et al., 1998a; Burashnikov and Antzelevitch, 2008; Wu et al., 2011) and shown in Figure 1) as well as by cAF-induced remodeling (Wagoner et al., 1997; Brandt et al., 2000; Christ et al., 2008). In addition, $\mathrm{I}_{\mathrm{Kur}}$ is primarily active during phase 2 of AP, and hence pure $\mathrm{I}_{\mathrm{Kur}}$ block exerted a relatively greater prolongation in $\mathrm{APD}_{30}$ than $\mathrm{APD}_{90}$ (Figure 3), in contrast to other $\mathrm{K}^{+}$-block including dofetilide which mediates anti-AF effects by prolonging the terminal phase of the AP (Roukoz and Saliba, 2007).

In this study, $\mathrm{I}_{\text {Kur }}$ block was simulated using a state-dependent block model, which successfully reproduced the use- and ratedependent inhibition of acacetin (Figure 1). The rate-dependent block of $\mathrm{I}_{\mathrm{Kur}}$ exerted a higher fractional inhibition in the current at faster pacing rates, which likely produces greater anti-AF effects in the presence of high-frequency excitations as seen during AF. Along with the previous modeling studies on investigating effects of $\mathrm{I}_{\mathrm{Kur}}$ block (Almquist et al., 2010; Scholz et al., 2013; Ellinwood et al., 2017), this study demonstrated the importance of explicitly considering the kinetic properties of the block in computational efforts of understanding the consequences and underlying mechanisms of $\mathrm{I}_{\text {Kur }}$ block.

\section{Effects of Combined $\mathrm{K}^{+}$-Current Block}

The combined $\mathrm{K}^{+}$-block (as exhibited by acacetin and many other $\mathrm{I}_{\mathrm{Kur}}$ blockers) resulted in synergistic APD prolongation as well as an increased efficacy in terminating re-entry in tissue as compared to the pure $\mathrm{I}_{\mathrm{Kur}}$ block.

Note that at the single myocyte level, the combined actions of acacetin produced greater prolongation in atrial APD than the sum of changes due to drug-induced block of individual channel in normal and cAF-remodeled myocytes (Figure 2). Additionally, the combined $\mathrm{K}^{+}$-block increased the rateadditivity of APD as compared to the pure $\mathrm{I}_{\text {Kur }}$ block (Online Supplementary Material 2.2). This was also consistently observed in the 1D simulation (Figure 5). In the setting of pure $\mathrm{I}_{\mathrm{Kur}}$ block, the elevated and prolonged plateau phase of the AP could promote the activation of $\mathrm{I}_{\mathrm{Kr}} / \mathrm{I}_{\mathrm{Ks}}$, which in return may accelerate the repolarization of AP-phase 3 (Colman et al., 2017). Therefore, additional inhibition in $\mathrm{I}_{\mathrm{Kr}}$ by an identical fraction is expected to result in a greater APD prolongation than a pure $\mathrm{I}_{\mathrm{Kur}}$ or $\mathrm{I}_{\mathrm{Kr}} / \mathrm{I}_{\mathrm{Ks}}$ block.

In $2 \mathrm{D}$ simulations, the combined $\mathrm{K}^{+}$-block produced an enhanced efficacy in suppressing AF compared with the pure $\mathrm{I}_{\text {Kur }}$ block: promoting meandering of rotor tips (Figure 7B), shortening the lifespan of re-entries (Figure $\mathbf{8 A}$ ) and slowing of spiral wave excitations (Figure 8B). Rotor meandering is one mechanism by which spiral waves may meet non-conducting boundaries to extinguish re-entry (Narayan et al., 2013; Pandit and Jalife, 2013; Rappel et al., 2015).

The effects of acacetin $(3.2 \mu \mathrm{M})$ on the ventricular AP and QT interval was assessed in a single cell model and $1 \mathrm{D}$ transmural strand model by assuming similar blockade effects of the compound on the human ventricles and atria. It was shown that following applying acacetin, the ventricular repolarization and QT interval was both preserved with slight prolongations around $21 \mathrm{~ms}$ (Figure 10). Our results are close to the previous experimental study (Li et al., 2008) showing that QT intervals were not prolonged by acacetin in isolated rabbit hearts and anesthetised dogs.

The synergistic effects demonstrated by the combined $\mathrm{K}^{+}$blocks have implications on developing novel pharmaceutical anti-AF therapies. Given that $\mathrm{I}_{\mathrm{to}}, \mathrm{I}_{\mathrm{Kr}}$ and $\mathrm{I}_{\mathrm{Ks}}$ contribute to the repolarizations of ventricular APs, inhibitions in these channels may promote risks of side effects in the ventricles. In this regard, combined block of atrial-specific $\mathrm{K}^{+}$channels may be favorable. Recently, another two families of $\mathrm{K}^{+}$-channels that are dominantly expressed in the atria have been acknowledged: the small-conductance $\mathrm{Ca}^{2+}$-activated $\mathrm{K}^{+}(\mathrm{SK})$ channels (ISK) (Qi et al., 2014), and the two-pore $\mathrm{K}^{+}(\mathrm{K} 2 \mathrm{P} 3.1)$ channel (I (Schmidt et al., 2015), further to the well-known constitutively active acetylcholine-activated $\mathrm{K}^{+}$current $\left(\mathrm{I}_{\mathrm{K}, \mathrm{ACh}}\right)$. Combined block of these atrial-specific channels may exert greater and safer antiarrhythmic effects in the atria, warranting future investigations.

\section{Synergistic Effects of Combined $\mathrm{Na}^{+}$- and $\mathrm{K}^{+}$- Block}

The present study reveals novel and significant synergistic effects of combined block of $\mathrm{Na}^{+}-$and $\mathrm{K}^{+}$-currents ( $\mathrm{I}_{\mathrm{Na}}$ and pure- $\mathrm{I}_{\mathrm{Kur}} / \mathrm{multi} \mathrm{K}^{+}$-block) and demonstrates the additional synergistic anti-arrhythmic effects derived from the multi- $\mathrm{K}^{+}$ channel block in cAF-remodeled atria.

In cAF-remodeled atria, combined $\mathrm{Na}^{+}$- and $\mathrm{K}^{+}$-block significantly increased the fractional $\mathrm{I}_{\mathrm{Na}}$ inhibition and APD prolongation (Figures 3,4) and promoted pronounced AP alternans at $6 \mathrm{~Hz}$, with complex effects in human AF (Narayan et al., 2011). In the simulations varying the blockade kinetics of $\mathrm{I}_{\mathrm{Na}}$ block, the combined block dramatically augmented the attainable maximal AF-selectivity in consequence of enhanced atrial-selectivity and rate-selectivity as compared to the pure $\mathrm{Na}^{+}$-block (Figure 6).

In the $1 \mathrm{D}$ model of an atrial strand, combined $\mathrm{Na}^{+}$and $\mathrm{K}^{+}$-block produced synergistic reductions in $\mathrm{V}_{\max }$ and $\mathrm{CV}$; the threshold of BCL allowing a 1:1 conduction was increased as compared to the control conditions (Figure 5). In simulated re-entrant waves in $2 \mathrm{D}$ and $3 \mathrm{D}$ atria, the combined $\mathrm{Bl} \cdot \mathrm{I}_{\mathrm{Na}}+$ Comb. Bl. IX exhibited a greater efficacy in suppressing AF, with a decreased lifespan of rotors as compared to that by either individual block (Figures 7-9). Although the combined $\mathrm{Bl} \cdot \mathrm{I}_{\mathrm{Na}}$ $+\mathrm{Bl} \cdot \mathrm{I}_{\mathrm{Kur}}$ did not further reduce the lifespan of spiral waves as compared to the $\mathrm{Bl} \cdot \mathrm{I}_{\mathrm{Na}}$ alone, the combination did lead to the extinction of one of the two rotors (Figures 7Aiv,Biv) and deceleration of re-entrant activations (Figure 8B). Follow-up simulations showed that consistent synergistic antiarrhythmic effects could be obtained with reduced doses of $\mathrm{Na}^{+}$- and $\mathrm{K}^{+}$blockers.

The non-specific multi-channel blockade is increasingly recognized as a strategy for pharmaceutical therapy of AF both experimentally (Sicouri et al., 2010; Aguilar et al., 2015; 
Kirchhoff et al., 2015; Hartmann et al., 2016) and clinically (Koskinas et al., 2014; Reiffel et al., 2015). In a previous study (Aguilar et al., 2015), synergistic anti-arrhythmic effects were demonstrated both in silico and experimentally in healthy canine hearts. Additionally, the favorable synergistic antiarrhythmic effects have also been reported in combined block of $\mathrm{I}_{\mathrm{SK}}$ and $\mathrm{I}_{\mathrm{Na}}$ in an experimental atrial-fibrillated guinea pig model (Kirchhoff et al., 2015). Also, the recent HARMONY trial (Reiffel et al., 2015) revealed synergistic AF-suppressing effects for combined use of ranolazine and dronedarone. While revealing the synergistic effects of combined $\mathrm{Na}^{+}$- and $\mathrm{K}^{+}$- block in cAF-remodeled human atria, this study supports and adds insights into the ongoing efforts in developing multi-channel block as a strategy for the treatment of AF.

\section{Limitations and Future Work}

In the absence of the required detailed experimental data, when simulating effects of acacetin on $\mathrm{I}_{\text {to }}, \mathrm{I}_{\mathrm{Ks}}$ and $\mathrm{I}_{\mathrm{Kr}}$, the dosedependence block of acacetin was assumed to be identical in both human atrial and ventricular cells. This assumption may warrant further investigations. In addition, the parameters of atrial $I_{\text {to }}$ have been reported to be different from those of ventricular $\mathrm{I}_{\text {to }}$ in human (Amos et al., 1996). Previous studies reported that the $\mathrm{IC}_{50}$ of 4-AP block of atrial $\mathrm{I}_{\text {to }}$ was one-third of that of ventricular $I_{\text {to }}$ (Amos et al., 1996; Nattel et al., 2000). If a similar atrial-vs.-ventricular difference in the $\mathrm{IC}_{50}$ of $\mathrm{I}_{\mathrm{to}}$ and/or $\mathrm{I}_{\mathrm{Kr}} / \mathrm{I}_{\mathrm{Ks}}$ could exist for acacetin, the effects of acacetin on the ventricular electrophysiology would be less significant than our simulations, which might result in to a smaller change in ventricular $\mathrm{I}_{\mathrm{Na}}$ and APD for the combined block of $\mathrm{Bl} \cdot \mathrm{I}_{\mathrm{Na}}$ and $\mathrm{Comb} \cdot \mathrm{Bl} \cdot \mathrm{I}_{\mathrm{X}}$, and thus enhance the computed atrial-selectivity and AF-selectivity of the combined block. Given that applying acacetin in vivo did not prolong QT intervals in isolated rabbit hearts and anesthetised dogs (Li et al., 2008), any significant prolongation of the ventricular APD and QT interval is unlikely (Figures 3B, 4C, 10). Therefore, our assumption of no atrial-ventricular difference in the potency of acacetin on $\mathrm{K}^{+}$-currents may not affect our conclusions concerning the atrial-selectivity of combined $\mathrm{Na}^{+}$and $\mathrm{K}^{+}$-block.

Additionally, in the absence of detailed experimental data for state-dependent block of $\mathrm{I}_{\mathrm{to}}, \mathrm{I}_{\mathrm{Kr}}$, and $\mathrm{I}_{\mathrm{Ks}}$ by acacetin, the block of these channels was modeled using a single pore block model. The IC50 values (Table 1) were determined by fitting the concentration-response relation of the step current at $40 \mathrm{mV}$ in previous experimental studies (Li et al., 2008; Wu et al., 2011). A recent study suggests that the IC50 values may be dependent on the voltage protocols applied, and this cannot be reflected by single pore models. In future studies, the pore block model for $\mathrm{I}_{\mathrm{to}}, \mathrm{I}_{\mathrm{Kr}}$, and $\mathrm{I}_{\mathrm{Ks}}$ can be replaced by a state-dependent block model when such experimental data become available. Also, the present work did not attempt to model the effects of acacetin on $\mathrm{I}_{\mathrm{K}, \mathrm{ACh}}$, although the study shows the current is potently blocked by the compound. The $2 \mathrm{D}$ and $3 \mathrm{D}$ simulations of atrial tissue, while validated, may not fully capture the complexity of fibrosis-tissue interfaces which are seen in structurally remodeled atria and were not simulated in these monodomain experiments.
Thirdly, our simulation results showed a moderate QT prolongation of around $20 \mathrm{~ms}$ following applying both $\mathrm{I}_{\mathrm{Na}}$ blocker and acacetin. While a QT prolongation of less than $5 \mathrm{~ms}$ does not raise a regulatory concern (Committee for Medicinal Products for Human Use, 2012), implications of QT prolongations between 5 and $20 \mathrm{~ms}$ remain inconclusive (Committee for Medicinal Products for Human Use, 2005). In the present study, though the extent of QT prolongation of $20 \mathrm{~ms}$ is far less than the threshold of discontinuation criteria of $60 \mathrm{~ms}$ as indicated in Committee for Medicinal Products for Human Use (2005), it would indeed raise a positive flag in thorough QT tests and necessitate extended safety assessment and intensive patient monitoring during late stages of trials (Committee for Medicinal Products for Human Use, 2012). On the other hand, the approach we used in accounting for the effects of acacetin on ventricular myocytes may result in upper bound of QT prolongation, since the potency of acacetin was assumed to be identical in atria and ventricles.

Fourthly, the threshold in BCL inducing AP alternans was increased by $\mathrm{K}^{+}$-block (Figure 5, Figure S5). However, AP alternans seen at slower pacing rates has been linked with occurrence of AF (Narayan et al., 2002, 2011). Therefore, the increased threshold in BCL developing $\mathrm{AF}$ by $\mathrm{K}^{+}$-block can be potentially proarrhythmic. The safety of $\mathrm{K}^{+}$-block and its proarrhythmic potential in the atria should be addressed in future studies.

Fifthly, there are limitations in the approaches used in simulating the $\mathrm{I}_{\mathrm{Na}}$ blockers in single myocytes and tissue. Similar to previous studies (Aguilar-Shardonofsky et al., 2012; Aguilar et al., 2015), in our simulations, the drug action on $\mathrm{I}_{\mathrm{Na}}$ was modeled through a state-dependent block assuming drugs binding to both activated and inactivated states of $\mathrm{I}_{\mathrm{Na}}$, and the gating variables of $\mathrm{I}_{\mathrm{Na}}$ were modeled using an HodgkinHuxley scheme. The limitations in this approach outlined in Aguilar-Shardonofsky et al. (2012) therefore apply in the present study. The results of the use-dependent block may be affected by the models used (Aguilar-Shardonofsky et al., 2012). However, the previous study (Aguilar-Shardonofsky et al., 2012) compared this modeling scheme with simulations using a Markov model, showing qualitative agreement in major findings. Therefore, the major conclusions drawn from this study may not be affected by the selected modeling approach for $\mathrm{I}_{\mathrm{Na}}$ and drug interactions. Furthermore, in optimizing the AFselectivity of the $\mathrm{I}_{\mathrm{Na}}$ and $\mathrm{K}^{+}$-current blockers, the concentrations of $\mathrm{Na}^{+}$and $\mathrm{K}^{+}$blockers were fixed at $60 \mathrm{uM}$. This may potentially impose limitations in discomposing the role of the binding parameters in the modulatory effects of the blockers because of the very slow kinetics of the drug binding to its targeted channel at this high concentration. It warrants further studies by varying the concentration of blockers to simulate the optimized effects of the AF-selectivity of $\mathrm{I}_{\mathrm{Na}}$ blocker. In tissue simulations, effects of drugs were modeled by increasing their doses homogeneously, simultaneously and instantaneously. The realistic actions of $\mathrm{I}_{\mathrm{Na}}$ blockers in tissue, however, may be different. Also, in tissue simulations a homogenous cell model was used. As previous study (Feng et al., 1998b) showed atria are electrically heterogeneous, future work is needed to 
assess how tissue heterogeneities affect the efficacy of atrialselective pharmaceutical interventions. Furthermore, the current simulations did not take the cardiac autonomic regulation into account in order to take into considerations of acacetin on $\mathrm{I}_{\mathrm{KACh}}$. Future studies on interactions of atrial-selective anti-arrhythmic drug actions and autonomic systems may also render valuable findings.

It is important to acknowledge that administration of class Ic agents for $\mathrm{Na}^{+}$-block can cause cardiac arrhythmia and increased mortality (Echt et al., 1991). Further investigations are therefore warranted to assess the safety of the simulated $\mathrm{Na}^{+}$-block in the heart, especially in the ventricles.

\section{CONCLUSIONS}

By using state-dependent drug block models and our mathematical models of the human atria, the antiarrhythmic effects of atrial selective $\mathrm{Na}^{+}$- and $\mathrm{K}^{+}$-blockers on the cAFremodeled atria were evaluated. The combined block of multiple $\mathrm{K}^{+}$-currents as well as simultaneous block of $\mathrm{Na}^{+}$- and $\mathrm{K}^{+}$currents produced synergistic antiarrhythmic effects. Our results suggest that developing multi-channel (multiple $\mathrm{K}^{+}$currents and/or combined $\mathrm{Na}^{+}$- and $\mathrm{K}^{+}$-current) block is a potentially valuable strategy for the treatment of AF.

\section{REFERENCES}

Aguilar, M., Feng, J., Vigmond, E., Comtois, P., and Nattel, S. (2017). Ratedependent role of IKur in human atrial repolarization and atrial fibrillation maintenance. Biophys. J. 112, 1997-2010. doi: 10.1016/j.bpj.2017.03.022

Aguilar, M., Xiong, F., Qi, X. Y., Comtois, P., and Nattel, S. (2015). Potassium channel blockade enhances atrial fibrillation-selective antiarrhythmic effects of optimized state-dependent sodium channel blockade. Circulation 132, 2203-2211. doi: 10.1161/CIRCULATIONAHA.115.018016

Aguilar-Shardonofsky, M., Vigmond, E. J., Nattel, S., and Comtois, P. (2012). In silico optimization of atrial fibrillation-selective sodium channel blocker pharmacodynamics. Biophys. J. 102, 951-960. doi: 10.1016/j.bpj.2012.01.032

Almquist, J., Wallman, M., Jacobson, I., and Jirstrand, M. (2010). Modeling the effect of Kv1.5 block on the canine action potential. Biophys. J. 99, 2726-2736. doi: 10.1016/j.bpj.2010.08.062

Amos, G. J., Wettwer, E., Metzger, F., Li, Q., Himmel, H. M., and Ravens, U. (1996). Differences between outward currents of human atrial and subepicardial ventricular myocytes. J. Physiol. 491, 31-50. doi: 10.1113/jphysiol.1996.sp021194

Antzelevitch, C., and Burashnikov, A. (2009). Atrial-selective sodium channel block as a novel strategy for the management of atrial fibrillation. J. Electrocardiol. 42, 543-548. doi: 10.1016/j.jelectrocard.2009.07.007

Aslanidi, O. V., Colman, M. A., Stott, J., Dobrzynski, H., Boyett, M. R., Holden, A. V., et al. (2011). 3D virtual human atria: a computational platform for studying clinical atrial fibrillation. Prog. Biophys. Mol. Biol. 107, 156-168. doi: 10.1016/j.pbiomolbio.2011.06.011

Baher, A., Qu, Z., Hayatdavoudi, A., Lamp, S. T., Yang, M.-J., Xie, F., et al. (2006). Short-term cardiac memory and mother rotor fibrillation. Am. J. Physiol. Heart Circ. Physiol. 292, H180-H189. doi: 10.1152/ajpheart.00944.2005

Bosch, R. F., Zeng, X., Grammer, J. B., Popovic, K., Mewis, C., and Kühlkamp, V. (1999). Ionic mechanisms of electrical remodeling in human atrial fibrillation. Cardiovasc. Res. 44, 121-131. doi: 10.1016/S0008-6363(99) 00178-9

Brandt, M. C., Priebe, L., Böhle, T., Südkamp, M., and Beuckelmann, D. J. (2000). The ultrarapid and the transient outward $\mathrm{K}^{+}$current in human atrial fibrillation: their possible role in postoperative atrial fibrillation. J. Mol. Cell. Cardiol. 32, 1885-1896. doi: 10.1006/jmcc.2000.1221

\section{AUTHOR CONTRIBUTIONS}

$\mathrm{HZ}$ and HN conceived the study. HN designed experiments, developed and validated computational models, and performed numerical experiments. HN, DW, and WW analyzed data. HN, DW, WW, WG, SN, and HZ interpreted data and wrote the manuscript.

\section{FUNDING}

This work was supported by grants from the British Heart Foundation FS/14/5/30533, EPSRC (UK) $\quad(\mathrm{EP} / \mathrm{J} 00958 \mathrm{X} / 1 ; \quad \mathrm{EP} / \mathrm{I029826/1)}, \quad$ MC-IRSES CORDIS3D (317766), NSFC (61179009), Shenzhen Science and Technology Innovation Committee (JCYJ20151029173639477; JSGG20160229125049615). SN is supported by grants from the National Institutes of Health (R01 Hl83359).

\section{SUPPLEMENTARY MATERIAL}

The Supplementary Material for this article can be found online at: https://www.frontiersin.org/articles/10.3389/fphys. 2017.00946/full\#supplementary-material

Brennan, T., Fink, M., and Rodriguez, B. (2009). Multiscale modelling of druginduced effects on cardiac electrophysiological activity. Eur. J. Pharm. Sci. 36, 62-77. doi: 10.1016/j.ejps.2008.09.013

Burashnikov, A., and Antzelevitch, C. (2008). Can inhibition of IKur promote atrial fibrillation? Heart Rhythm 5, 1304-1309. doi: 10.1016/j.hrthm.2008.05.020

Burashnikov, A., Diego, J. M. D., Zygmunt, A. C., Belardinelli, L., and Antzelevitch, C. (2007). Atrium-selective sodium channel block as a strategy for suppression of atrial fibrillation differences in sodium channel inactivation between atria and ventricles and the role of ranolazine. Circulation 116, 1449-1457. doi: 10.1161/CIRCULATIONAHA.107.704890

Caves, R. E., Cheng, H., Choisy, S. C., Gadeberg, H. C., Bryant, S. M., Hancox, J. C., et al. (2017). Atrial-ventricular differences in rabbit cardiac voltage-gated $\mathrm{Na}^{+}$currents: basis for atrial-selective block by ranolazine. Heart Rhythm. 14, 1657-1664. doi: 10.1016/j.hrthm.2017.06.012

Chen, K.-H., Xu, X.-H., Sun, H.-Y., Du, X.-L., Liu, H., Yang, L., et al. (2016). Distinctive property and pharmacology of voltage-gated sodium current in rat atrial versus ventricular myocytes. Heart Rhythm. 13, 762-770. doi: 10.1016/j.hrthm.2015.11.022

Christ, T., Wettwer, E., Voigt, N., Hála, O., Radicke, S., Matschke, K., et al. (2008). Pathology-specific effects of the IKur/Ito/IK,ACh blocker AVE0118 on ion channels in human chronic atrial fibrillation. Br. J. Pharmacol. 154, 1619-1630. doi: 10.1038/bjp.2008.209

Clayton, R. H., Bernus, O., Cherry, E. M., Dierckx, H., Fenton, F. H., Mirabella, L., et al. (2011). Models of cardiac tissue electrophysiology: progress, challenges and open questions. Prog. Biophys. Mol. Biol. 104, 22-48. doi: 10.1016/j.pbiomolbio.2010.05.008

Colman, M. A., Aslanidi, O. V., Kharche, S., Boyett, M. R., Garratt, C., Hancox, J. C., et al. (2013). Pro-arrhythmogenic effects of atrial fibrillation-induced electrical remodelling: insights from the three-dimensional virtual human atria. J. Physiol. 591, 4249-4272. doi: 10.1113/jphysiol.2013.254987

Colman, M. A., Ni, H., Liang, B., Schmitt, N., and Zhang, H. (2017). In silico assessment of genetic variation in KCNA5 reveals multiple mechanisms of human atrial arrhythmogenesis. PLoS Comput. Biol. 13:e1005587. doi: 10.1371/journal.pcbi.1005587

Committee for Medicinal Products for Human Use (2005). ICH Note for Guidance on the Clinical Evaluation of QT/QTc Interval Prolongation and Proarrhythmic Potential for Non-antiarrhythmic Drugs (ICH E14) (CHMP/ICH/2/04). 
London: EMEA. Available online at: http://www.ema.europa.eu/docs/en_GB/ document_library/Scientific_guideline/2009/09/WC500002879.pdf

Committee for Medicinal Products for Human Use (2012). ICH Topic E14: The Clinical Evaluation of QT/QTc Interval Prolongation and Proarrhythmic Potential for Non-antiarrhythmic Drugs Questions and Answers (EMA/CHMP/ICH/310133/2008). London: EMEA. Available online at: http:// www.ema.europa.eu/docs/en_GB/document_library/Scientific_guideline/ 2009/09/WC500002878.pdf

Dobrev, D., Carlsson, L., and Nattel, S. (2012). Novel molecular targets for atrial fibrillation therapy. Nat. Rev. Drug Discov. 11, 275-291. doi: 10.1038/nrd3682

Dobrev, D., and Ravens, U. (2003). Remodeling of cardiomyocyte ion channels in human atrial fibrillation. Basic Res. Cardiol. 98, 137-148. doi: 10.1007/s00395-003-0409-8

Echt, D. S., Liebson, P. R., Mitchell, L. B., Peters, R. W., Obias-Manno, D., Barker, A. H., et al. (1991). Mortality and morbidity in patients receiving encainide, flecainide, or placebo. N. Engl. J. Med. 324, 781-788. doi: 10.1056/NEJM199103213241201

Ellinwood, N., Dobrev, D., Morotti, S., and Grandi, E. (2017). Revealing kinetics and state-dependent binding properties of IKur-targeting drugs that maximize atrial fibrillation selectivity. Chaos Interdiscip. J. Nonlinear Sci. 27:093918. doi: $10.1063 / 1.5000226$

Fan, X., Wang, C., Wang, N., Ou, X., Liu, H., Yang, Y., et al. (2016). Atrial-selective block of sodium channels by acehytisine in rabbit myocardium. J. Pharmacol. Sci. 132, 235-243. doi: 10.1016/j.jphs.2016.03.014

Feng, J., Xu, D., Wang, Z., and Nattel, S. (1998a). Ultrarapid delayed rectifier current inactivation in human atrial myocytes: properties and consequences. Am. J. Physiol. Heart Circ. Physiol. 275, H1717-H1725.

Feng, J., Yue, L., Wang, Z., and Nattel, S. (1998b). Ionic mechanisms of regional action potential heterogeneity in the canine right atrium. Circ. Res. 83, 541-551. doi: 10.1161/01.RES.83.5.541

Ford, J., Milnes, J., El Haou, S., Wettwer, E., Loose, S., Matschke, K., et al. (2016). The positive frequency-dependent electrophysiological effects of the Ikur inhibitor Xen-D0103 are desirable for the treatment of atrial fibrillation. Heart Rhythm. 13, 555-564. doi: 10.1016/j.hrthm.2015.10.003.

Gima, K., and Rudy, Y. (2002). Ionic current basis of electrocardiographic waveforms a model study. Circ. Res. 90, 889-896. doi: 10.1161/01.RES.0000016960.61087.86

Gögelein, H., Brendel, J., Steinmeyer, K., Strübing, C., Picard, N., Rampe, D., et al. (2004). Effects of the atrial antiarrhythmic drug AVE0118 on cardiac ion channels. Naunyn. Schmiedebergs Arch. Pharmacol. 370, 183-192. doi: 10.1007/s00210-004-0957-y

Grandi, E., Pandit, S. V., Voigt, N., Workman, A. J., Dobrev, D., Jalife, J., et al. (2011). Human atrial action potential and $\mathrm{Ca}^{2+}$ model sinus rhythm and chronic atrial fibrillation. Circ. Res. 109, 1055-1066. doi: 10.1161/CIRCRESAHA.111.253955

Haan, S., de Greiser, M., Harks, E., Blaauw, Y., Hunnik, A., van Verheule, S., et al. (2006). AVE0118, blocker of the transient outward current (Ito) and ultrarapid delayed rectifier current (IKur), fully restores atrial contractility after cardioversion of atrial fibrillation in the goat. Circulation 114, 1234-1242. doi: 10.1161/CIRCULATIONAHA.106.630905

Hancox, J. C., James, A. F., Marrion, N. V., Zhang, H., and Thomas, D. (2016). Novel ion channel targets in atrial fibrillation. Expert Opin. Ther. Targets 20, 947-958. doi: 10.1517/14728222.2016.1159300

Hartmann, N., Mason, F. E., Braun, I., Pabel, S., Voigt, N., Schotola, H., et al. (2016). The combined effects of ranolazine and dronedarone on human atrial and ventricular electrophysiology. J. Mol. Cell. Cardiol. 94, 95-106. doi: 10.1016/j.yjmcc.2016.03.012

Hondeghem, L. M., and Snyders, D. J. (1990). Class III antiarrhythmic agents have a lot of potential but a long way to go. Reduced effectiveness and dangers of reverse use dependence. Circulation 81, 686-690. doi: 10.1161/01.CIR.81. 2.686

Jarman, J. W. E., Wong, T., Kojodjojo, P., Spohr, H., Davies, J. E., Roughton, M., et al. (2012). Spatiotemporal behavior of high dominant frequency during paroxysmal and persistent atrial fibrillation in the human left atrium. Circ. Arrhythm. Electrophysiol. 5, 650-658. doi: 10.1161/CIRCEP.111.967992

Kirchhoff, J. E., Goldin Diness, J., Sheykhzade, M., Grunnet, M., and Jespersen, T. (2015). Synergistic antiarrhythmic effect of combining inhibition of $\mathrm{Ca}^{2+}$-activated $\mathrm{K}^{+}(\mathrm{SK})$ channels and voltage-gated $\mathrm{Na}+$ channels in an isolated heart model of atrial fibrillation. Heart Rhythm 12, 409-418. doi: 10.1016/j.hrthm.2014.12.010

Koskinas, K. C., Fragakis, N., Katritsis, D., Skeberis, V., and Vassilikos, V. (2014). Ranolazine enhances the efficacy of amiodarone for conversion of recent-onset atrial fibrillation. Europace 16, 973-979. doi: 10.1093/europace/eut407

Li, G.-R., Lau, C.-P., and Shrier, A. (2002). Heterogeneity of sodium current in atrial vs. epicardial ventricular myocytes of adult guinea pig hearts. J. Mol. Cell. Cardiol. 34, 1185-1194. doi: 10.1006/jmcc.2002.2053

Li, G.-R., Wang, H.-B., Qin, G.-W., Jin, M.-W., Tang, Q., Sun, H.-Y., et al. (2008). Acacetin, a natural flavone, selectively inhibits human atrial repolarization potassium currents and prevents atrial fibrillation in dogs. Circulation 117 2449-2457. doi: 10.1161/CIRCULATIONAHA.108.769554

Loose, S., Mueller, J., Wettwer, E., Knaut, M., Ford, J., Milnes, J., et al. (2014). Effects of IKur blocker MK-0448 on human right atrial action potentials from patients in sinus rhythm and in permanent atrial fibrillation. Pharmacol. Ion Channels Channelopathies 5:26. doi: 10.3389/fphar.2014.00026

Luo, C. H., and Rudy, Y. (1994). A dynamic model of the cardiac ventricular action potential. I. Simulations of ionic currents and concentration changes. Circ. Res. 74, 1071-1096. doi: 10.1161/01.RES.74.6.1071

Moreno, J. D., Zhu, Z. I., Yang, P.-C., Bankston, J. R., Jeng, M.-T., Kang, C., et al. (2011). A computational model to predict the effects of class i anti-arrhythmic drugs on ventricular rhythms. Sci. Transl. Med. 3:98ra83. doi: 10.1126/scitranslmed.3002588

Morotti, S., McCulloch, A. D., Bers, D. M., Edwards, A. G., and Grandi, E. (2016). Atrial-selective targeting of arrhythmogenic phase-3 early afterdepolarizations in human myocytes. J. Mol. Cell. Cardiol. 96, 63-71. doi: 10.1016/j.yjmcc.2015.07.030

Narayan, S. M., Bode, F., Karasik, P. L., and Franz, M. R. (2002). Alternans of atrial action potentials during atrial flutter as a precursor to atrial fibrillation. Circulation 106, 1968-1973. doi: 10.1161/01.CIR.0000037062.35762.B4

Narayan, S. M., Franz, M. R., Clopton, P., Pruvot, E. J., and Krummen, D. E. (2011). Repolarization alternans reveals vulnerability to human atrial fibrillation. Circulation 123, 2922-2930. doi: 10.1161/CIRCULATIONAHA.110.977827

Narayan, S. M., Shivkumar, K., Krummen, D. E., Miller, J. M., and Rappel, W.-J. (2013). Panoramic electrophysiological mapping but not electrogram morphology identifies stable sources for human atrial fibrillation. Circ. Arrhythm. Electrophysiol. 6, 58-67. doi: 10.1161/CIRCEP.111.977264

Nattel, S., and Dobrev, D. (2017). Controversies about atrial fibrillation mechanisms: aiming for order in chaos and whether it matters. Circ. Res. 120, 1396-1398. doi: 10.1161/CIRCRESAHA.116.310489

Nattel, S., Matthews, C., Blasio, E. D., Han, W., Li, D., and Yue, L. (2000). Dose-dependence of 4-aminopyridine plasma concentrations and electrophysiological effects in dogs potential relevance to ionic mechanisms in vivo. Circulation 101, 1179-1184. doi: 10.1161/01.CIR.101.10.1179

O'Hara, T., Virág, L., Varr,ó, A., and Rudy, Y. (2011). Simulation of the undiseased human cardiac ventricular action potential: model formulation and experimental validation. PLoS Comput Biol 7:e1002061. doi: 10.1371/journal.pcbi.1002061

Osaka, T., Itoh, A., and Kodama, I. (2000). Action potential remodeling in the human right atrium with chronic lone atrial fibrillation. Pacing Clin. Electrophysiol. 23, 960-965. doi: 10.1111/j.1540-8159.2000.tb00881.x

Pandit, S. V., and Jalife, J. (2013). Rotors and the dynamics of cardiac fibrillation. Circ. Res. 112, 849-862. doi: 10.1161/CIRCRESAHA.111.300158

Pavri, B. B., Greenberg, H. E., Kraft, W. K., Lazarus, N., Lynch, J. J., Salata, J. J., et al. (2012). Mk-0448, a specific Kv1.5 inhibitor safety, pharmacokinetics, and pharmacodynamic electrophysiology in experimental animal models and humans. Circ. Arrhythm. Electrophysiol. 5, 1193-1201. doi: 10.1161/CIRCEP.111.969782

Persson, F., Carlsson, L., Duker, G., and Jacobson, I. (2005). Blocking characteristics of hKv1.5 and hKv4.3/hKChIP2.2 after administration of the novel antiarrhythmic compound AZD7009. J. Cardiovasc. Pharmacol. 46, 7-17. doi: 10.1097/01.fjc.0000161405.37198.c1

Qi, X.-Y., Diness, J. G., Brundel, B. J. J. M., Zhou, X.-B., Naud, P., Wu, C.-T., et al. (2014). Role of small-conductance calcium-activated potassium channels in atrial electrophysiology and fibrillation in the dog. Circulation 129, 430-440. doi: 10.1161/CIRCULATIONAHA.113.003019

Rappel, W.-J., Zaman, J. A. B., and Narayan, S. M. (2015). Mechanisms for the termination of atrial fibrillation by localized ablation: computational 
and clinical studies. Circ. Arrhythm. Electrophysiol. 8, 1325-1333. doi: 10.1161/CIRCEP.115.002956

Ravens, U., and Wettwer, E. (2011). Ultra-rapid delayed rectifier channels: molecular basis and therapeutic implications. Cardiovasc. Res. 89, 776-785. doi: $10.1093 / \mathrm{cvr} / \mathrm{cvq} 398$

Reiffel, J. A., Camm, A. J., Belardinelli, L., Zeng, D., Karwatowska-Prokopczuk, E., Olmsted, A., et al. (2015). The HARMONY trial: combined ranolazine and dronedarone in the management of paroxysmal atrial fibrillation: mechanistic and therapeutic synergism. Circ. Arrhythm. Electrophysiol. 8, 1048-1056. doi: 10.1161/CIRCEP.115.002856

Roukoz, H., and Saliba, W. (2007). Dofetilide: a new class III antiarrhythmic agent. Expert Rev. Cardiovasc. Ther. 5, 9-19. doi: 10.1586/14779072.5.1.9

Schmidt, C., Wiedmann, F., Voigt, N., Zhou, X.-B., Heijman, J., Lang, S., et al. (2015). Upregulation of K2P3.1 $\mathrm{K}^{+}$current causes action potential shortening in patients with chronic atrial fibrillation. Circulation 132, 82-92. doi: 10.1161/CIRCULATIONAHA.114.012657

Scholz, E. P., Carrillo-Bustamante, P., Fischer, F., Wilhelms, M., Zitron, E., Dössel, O., et al. (2013). Rotor termination is critically dependent on kinetic properties of IKur inhibitors in an in silico model of chronic atrial fibrillation. PLOS ONE 8:e83179. doi: 10.1371/journal.pone.0083179

Schotten, U., Haan, S., de Verheule, S., Harks, E. G. A., Frechen, D., Bodewig, E., et al. (2007). Blockade of atrial-specific $\mathrm{K}^{+}$-currents increases atrial but not ventricular contractility by enhancing reverse mode $\mathrm{Na}^{+} / \mathrm{Ca}^{2+}$-exchange. Cardiovasc. Res. 73, 37-47. doi: 10.1016/j.cardiores.2006.11.024

Sicouri, S., Burashnikov, A., Belardinelli, L., and Antzelevitch, C. (2010). Synergistic electrophysiologic and antiarrhythmic effects of the combination of ranolazine and chronic amiodarone in canine atria. Circ. Arrhythm. Electrophysiol. 3, 88-95. doi: 10.1161/CIRCEP.109.886275

Tamargo, J., Caballero, R., Gómez, R., and Delpón, E. (2009). IKur/Kv1.5 channel blockers for the treatment of atrial fibrillation. Expert Opin. Investig. Drugs 18, 399-416. doi: 10.1517/13543780902762850

Tsujimae, K., Murakami, S., and Kurachi, Y. (2008). In silico study on the effects of IKur block kinetics on prolongation of human action potential after atrial fibrillation-induced electrical remodeling. Am. J. Physiol. Heart Circ. Physiol. 294, H793-H800. doi: 10.1152/ajpheart.01229.2007

Voigt, N., and Dobrev, D. (2016). Atrial-selective potassium channel blockers. Card. Electrophysiol. Clin. 8, 411-421. doi: 10.1016/j.ccep.2016.02.005

Voigt, N., Li, N., Wang, Q., Wang, W., Trafford, A. W., Abu-Taha, I., et al. (2012). Enhanced sarcoplasmic reticulum $\mathrm{Ca}^{2+}$ leak and increased $\mathrm{Na}^{+}-\mathrm{Ca}^{2+}$ exchanger function underlie delayed afterdepolarizations in patients with chronic atrial fibrillation. Circulation 125, 2059-2070. doi: 10.1161/CIRCULATIONAHA.111.067306

Wagoner, D. R. V., Pond, A. L., McCarthy, P. M., Trimmer, J. S., and Nerbonne, J. M. (1997). Outward $\mathrm{K}^{+}$current densities and Kv1.5 expression are reduced in chronic human atrial fibrillation. Circ. Res. 80, 772-781. doi: 10.1161/01.RES.80.6.772

Wettwer, E., Hála, O., Christ, T., Heubach, J. F., Dobrev, D., Knaut, M., et al. (2004). Role of ikur in controlling action potential shape and contractility in the human atrium influence of chronic atrial fibrillation. Circulation 110, 2299-2306. doi: 10.1161/01.CIR.0000145155.60288.71

Wettwer, E., and Terlau, H. (2014). Pharmacology of voltage-gated potassium channel Kv1.5-impact on cardiac excitability. Curr. Opin. Pharmacol. 15, 115-121. doi: 10.1016/j.coph.2014.02.001
Whittaker, D. G., Ni, H., Harchi, A. E., Hancox, J. C., and Zhang, H. (2017). Atrial arrhythmogenicity of KCNJ2 mutations in short QT syndrome: insights from virtual human atria. PLoS Comput. Biol. 13:e1005593. doi: 10.1371/journal.pcbi.1005593

Wilhelms, M., Maleckar, M. M., Koivumäki, J. T., Dössel, O., and Seemann, G. (2013). Benchmarking electrophysiological models of human atrial myocytes. Front. Comput. Physiol. Med. 3:487. doi: 10.3389/fphys.2012. 00487

Wirth, K. J., Brendel, J., Steinmeyer, K., Linz, D. K., Rütten, H., and Gögelein, H. (2007). In vitro and in vivo effects of the atrial selective antiarrhythmic compound AVE1231. J. Cardiovasc. Pharmacol. 49, 197-206. doi: 10.1097/FJC.0b013e318032002f

Woods, C. E., and Olgin, J. (2014). Atrial fibrillation therapy now and in the future drugs, biologicals, and ablation. Circ. Res. 114, 1532-1546. doi: 10.1161/CIRCRESAHA.114.302362

Workman, A. J., Kane, K. A., and Rankin, A. C. (2001). The contribution of ionic currents to changes in refractoriness of human atrial myocytes associated with chronic atrial fibrillation. Cardiovasc. Res. 52, 226-235. doi: 10.1016/S0008-6363(01)00380-7

Wu, H.-J., Wu, W., Sun, H.-Y., Qin, G.-W., Wang, H.-B., Wang, P., et al. (2011). Acacetin causes a frequency- and use-dependent blockade of hKv1.5 channels by binding to the S6 domain. J. Mol. Cell. Cardiol. 51, 966-973. doi: 10.1016/j.yjmcc.2011.08.022

Yap, Y. G., and Camm, A. J. (2003). Drug induced QT prolongation and torsades de pointes. Heart 89, 1363-1372. doi: 10.1136/heart.89.11.1363

Yuan, Y., Bai, X., Luo, C., Wang, K., and Zhang, H. (2015). The virtual heart as a platform for screening drug cardiotoxicity. Br. J. Pharmacol. 172, 5531-5547. doi: 10.1111/bph.12996

Zhang, H., Garratt, C. J., Zhu, J., and Holden, A. V. (2005). Role of up-regulation of IK1 in action potential shortening associated with atrial fibrillation in humans. Cardiovasc. Res. 66, 493-502. doi: 10.1016/j.cardiores.2005. 01.020

Zhu, Y., Kyle, J. W., and Lee, P. J. (2006). Flecainide sensitivity of a $\mathrm{Na}$ channel long QT mutation shows an open-channel blocking mechanism for use-dependent block. Am. J. Physiol. Heart Circ. Physiol. 291, H29-H37. doi: 10.1152/ajpheart.01317.2005

Zygmunt, A. C., Nesterenko, V. V., Rajamani, S., Hu, D., Barajas-Martinez, H., Belardinelli, L., et al. (2011). Mechanisms of atrial-selective block of $\mathrm{Na}^{+}$channels by ranolazine: I. Experimental analysis of the usedependent block. Am. J. Physiol. Heart Circ. Physiol. 301, H1606-H1614. doi: 10.1152/ajpheart.00242.2011

Conflict of Interest Statement: The authors declare that the research was conducted in the absence of any commercial or financial relationships that could be construed as a potential conflict of interest.

Copyright (๑ $2017 \mathrm{Ni}$, Whittaker, Wang, Giles, Narayan and Zhang. This is an open-access article distributed under the terms of the Creative Commons Attribution License (CC BY). The use, distribution or reproduction in other forums is permitted, provided the original author(s) or licensor are credited and that the original publication in this journal is cited, in accordance with accepted academic practice. No use, distribution or reproduction is permitted which does not comply with these terms. 